\title{
Mercury transformations and exchanges in a high turbidity estuary
}

\author{
F. J. G. Laurier ${ }^{1}$, D. Cossa, ${ }^{\star}, 1$, J. L. Gonzalez ${ }^{2}$, E. Breviere ${ }^{1}$ and G. Sarazin ${ }^{3}$
}

\author{
1 Ifremer, BP 21105, F.44311, Nantes cedex 3, France \\ 2 Ifremer, BP 330, F.83507, La Seyne-sur-mer, France \\ ${ }^{3}$ Laboratoire de Géochimie des Eaux, Université Denis Diderot, 75005, Paris, France \\ *: Corresponding author : dcossa@ifremer.fr
}

\begin{abstract}
:
The speciation and partition of mercury in a macrotidal estuary (Seine estuary, France) was studied in order to explore the role of the high turbidity zone (HTZ) in mercury transfer to the adjacent coastal waters. Water and particles were analyzed to determine the concentrations of various mercury species, including monomethylmercury and the inorganic fraction. The exchangeable particulate mercury, which varies with salinity, and the mercury fraction associated with the amorphous oxyhydroxides were evaluated. The distribution of dissolved mercury species during early mixing suggests non-conservative behavior of organically bound mercury at the head of the estuary. Mercury in the particles covaried positively with suspended particulate matter concentrations up to a threshold, which constitutes the typical mercury load of particles and deposited sediments of the HTZ. This distribution pattern is well explained by a dilution model: a slowly settling, low metal population of particle, characterized by relatively invariant turbidity, becomes admixed with a variable amount of higher metal content particles derived from the resuspension in the HTZ. In addition, in the HTZ, which acts as a degradation reactor for particulate organic matter, particulate mercury concentrations increase with increasing $\mathrm{C}: \mathrm{N}$ ratios and amorphous oxyhydroxides particles. Mercury reaches the estuarine HTZ mainly associated with the riverine and marine particles, including organic matter and oxyhydroxides, which are temporarily trapped in the HTZ and mixed with autochthonous HTZ particles. The largest particles periodically settle and undergo diagenetic reactions and resuspensions, which lead to their mercury enrichment. Depending upon hydrodynamic conditions, mercury escapes seaward as fine particulate within the plume, partially associated with the oxyhydroxides. A surface complexation model reproduces most of the partitioning observed. In the dissolved phase the model simulation suggests that a very strong ligand must be present to explain the field observations.
\end{abstract}




\section{INTRODUCTION}

The mercury biogeochemical cycle in oceanic environments has given rise to significant papers overviewed by Fitzgerald and Mason (1997) and more recently by Mason and Sheu (2002). These authors noted the importance of biological and chemical transformations (mainly reduction/oxydation and methylation/demethylation), which govern the fate of this metal in aquatic environments: the role of dissolved gaseous mercury (DGM) in intense atmospheric recycling and the role of monomethylmercury (MMHg) in the bioaccumulation in the food webs. In coastal environments, the major exchange route between the continents and the oceans are via the atmosphere, while riverine inputs are small on a global scale (Cossa et al., 1996 ; Fitzgerald and Mason, 1997). However, rivers make a significant contribution to the mercury mass balance on a local scale, in coastal environments, through estuaries. Moreover, the riverine inputs accumulate in coastal areas and are a significant concern, from an environmental point of view. Indeed, from a mass balance approach in the Saint Lawrence estuary, it was concluded that the riverborne mercury is trapped or recycled within the estuarine and nearshore coastal waters ; insignificant amounts were transferred to the ocean (Cossa and Gobeil, 2000). Despite this observation, few studies have dealt with the scavenging processes in coastal zones, and their identification is still marked by speculation (e.g., Cossa et al. 1988; Guentzel et al., 1996; Stordal et al., 1996; Gagnon et al., 1996). In an early contribution, the first authors proposed a non conservative behavior for dissolved mercury in the Saint Lawrence estuary suggesting the flocculation of dissolved and/or colloidal mercury organic associations. Ionic strength or suspended matter gradients were advanced to account for this observation. This view was supported by Guentzel et al. (1996) and Stordal et al. (1996) in their studies of Texas and Florida estuaries. The latter authors show that colloidal mercury covaried with colloidal organic carbon. The former authors and 
the speciation measurements in waters from the Scheldt estuary (Leermarkers et al., 1995) suggest the presence of strongly bound mercury in the early mixing zone. In addition, a recent study pointed out the role of neutral mercury compounds in the partition changes of mercury during estuarine mixing (Turner et al., 2001 ; Le Roux et al., 2001).

High turbidity zones (HTZ) are a common feature of macrotidal estuaries, as a result of the high hydrodynamic energy present in these environments. They constitute a temporary trap for riverine particles, and consist of resuspension of settled particles, which periodically undergo diagenetic reactions in surface and sub-surface sediment driven by the oxidation of the organic matter. An organic matter/mercury relationship in coastal sediments is well established and the involvement of mercury in the iron and manganese oxidation-reduction cycles has been suggested (Gobeil and Cossa, 1993; Cossa et al., 1996; Gagnon et al., 1996). These authors propose that part of the mercury brought to the sediment with organic particles is released into pore water during the organic matter mineralization, and involved in a adsorption-desorption process as iron and manganese are reduced or oxidized in the benthic layer. The role of estuarine HTZ was less studied.

In this paper we address the following questions: (i) What is the role of the HTZ in the mercury transfer to the adjacent coastal waters? (ii) Is there a redistribution of the species between the dissolved and particulate phases? (iii) What are the roles of organic matter and oxyhydroxides in the process? (iv) What is the importance of methylated species? (v) To what extent can thermodynamic equilibria explain the speciation and partition observed? and (vi) what are the chemical forms of mercury escaping to the adjacent coastal area? We address these questions with, the Seine estuary (France, Fig. 1), an example of a high turbidity estuary where the HTZ is well developed (the concentrations usually range from 100 to 1000 mg. $\mathrm{l}^{-1}$ and the mass of suspension around $0.210^{9} \mathrm{~kg}$ ). The HTZ remains stable for months, independent of the river regime, but dependent mainly on the spring tide amplitude (up to 7 
m), and the renewal time of the HTZ by riverine particles, which has been estimated to be one year (Brenon and Le Hir, 1999 ; Le Hir et al., 2001). The Seine river estuary is one of the most heavily urbanized and industrialized estuaries in Europe and the mercury input in the Seine river, due to anthrogenic activities has been estimated at $50 \mathrm{~kg} \mathrm{year}^{-1}$ (Cossa et al., 2002a). Two other studies have been devoted to the mercury biogeochemical behaviour in this environment. Coquery et al. (1997) have described the partition and speciation of this metal from the River to the English Channel and Mikac et al. (1999) have described the total mercury and monomethylmercury distributions in sediment and sediment pore water. The role of the HTZ in mercury transformation and exchanges is yet to be described. This should provide a geochemical behavioural model applicable to other macrotidal estuaries. 


\section{MATERIALS AND METHODS}

\subsection{Sampling collection}

Two sampling cruises were made in 2000 onboard the research vessel R/V Thalia; the first, in February during flood conditions, and the second in August during low river discharge. Around 30 to 35 samples were taken at the stations shown on figure 1 . Details on the hydrodynamic conditions are shown in table 1.The samples were collected in 51 Teflon ${ }^{\circledR}$ bottles using an ultra-clean Teflon ${ }^{\circledR}$ pumping system, including a Teflon pump (AsTI, PCS ${ }^{\circledR}$ ) and Teflon ${ }^{\circledR}$ tubing. Samples were processed immediately after collection, or at least within 3 hours after collection, in an onboard clean container (class 100); this sampling technique prevented the sample from contacting the ship environment. Sample collection and treatment were performed using ultra-clean techniques. Polyethylene gloves were used for handling operations. All Teflon ${ }^{\circledR}$ and plastic-ware had been acid washed (3 days in 50\% $\mathrm{HNO}_{3}$, then 3 days in $10 \% \mathrm{HNO}_{3}$ at $50^{\circ} \mathrm{C}$ ) and rinsed several times with Milli-Q ${ }^{\circledR}$ water prior to use. Cleaned Teflon ${ }^{\circledR}$ bottles were filled with Milli-Q ${ }^{\circledR}$ water acidified with $\mathrm{HCl}(1 \% \mathrm{v} / \mathrm{v}$, Seastar $^{\circledR}$ ) and stored in double polyethylene bags until use. Beside $\mathrm{Hg}$, aliquots from the 5 liter Teflon ${ }^{\circledR}$ samples were used to determine $\mathrm{pH}$, dissolved organic carbon, particulate organic carbon, nitrogen, hydrogen and oxygen, phytoplankton pigment and nutrients. Samples were collected separately for the measurement of dissolved oxygen. In order to identify the water masses before the sampling, temperature and salinity were recorded in-situ with a CTD-probe. Plankton samples have been collected using a one meter diameter $20 \mu \mathrm{m}$ mesh net at $2 \mathrm{~m}$ below the surface. The plankton was then sorted on board in sub-samples onto 40, 150 and $1000 \mu \mathrm{m}$ Nylon nets, and kept frozen in polyethylene bags.

\subsection{Sample analysis}


Samples were analyzed for dissolved gaseous mercury (DGM), dissolved "reactive” or “easily reducible” mercury $\left((\mathrm{HgR})_{\mathrm{D}}\right)$, total dissolved mercury $\left((\mathrm{HgT})_{\mathrm{D}}\right)$, total particulate mercury $\left((\mathrm{HgT})_{\mathrm{P}}\right)$ and particulate mercury associated with the amorphous oxyhydroxides $\left((\operatorname{Hgox})_{\mathrm{P}}\right)$. All mercury species were detected by cold vapour atomic fluorescence spectrometry (AFS) after transformation to $\mathrm{Hg}^{0}$ (Bloom and Fitzgerald, 1988) using a Merlin ${ }^{\circledR}$ instrument (PSAnalytical) or a MLD-500 (Spectra-France). For the separation of "dissolved" and particulate mercury species, water samples were filtered on board ship through Teflon ${ }^{\circledR}$ filters (Millipore ${ }^{\circledR}$ LCR, $0.45 \mu \mathrm{m}$ ). Unfiltered aliquots were analyzed within $30 \mathrm{~min}$ after sampling for DGM; $500 \mathrm{ml}$ of water was sparged for $30 \mathrm{~min}$ with Hg-free argon at $300 \mathrm{ml}$ $\min ^{-1}$. The volatile Hg compounds were trapped on a gold trap and measured by AFS. Concentrations of $(\mathrm{HgR})_{\mathrm{D}}$ were determined within 3 hours using $\mathrm{SnCl}_{2}$ reduction. An aliquot of $50 \mathrm{ml}$ of filtered water was transferred into a Teflon ${ }^{\circledR}$ bubbler and $0.1 \mathrm{ml}$ of an acidic $\mathrm{SnCl}_{2}$ solution ( $50 \% \mathrm{SnCl}_{2} \mathrm{w} / \mathrm{v}, 15 \% \mathrm{HCl} \mathrm{v} / \mathrm{v}$ ) was added. The samples were then sparged for $9 \mathrm{~min}$ with Hg-free argon and the reduced species were trapped on a gold column and measured by AFS detection. Total dissolved mercury concentrations were also determined within 3 hours; the compounds were decomposed by bromine oxidation before the reduction step. (MMHg) was determined after hydride formation and cryogenic chromatographic separation according to Tseng et al. (1998), but using AFS instead of atomic absorption spectophotometry for detection. The suspended particulate matter (SPM) collected on the preweighed LCR ${ }^{\circledR}$ filters was reweighed to estimate the SPM load and digested with concentrated $\mathrm{HCl} / \mathrm{HNO}_{3}(1 / 9, \mathrm{v} / \mathrm{v})$ in Teflon ${ }^{\circledR}$ (PFA, Savillex) reactors $\left(90^{\circ} \mathrm{C} ; 3 \mathrm{~h}\right)$ in order to determine $(\mathrm{HgT})_{\mathrm{P}}$ concentrations. The protocols are detailed in Quémerais and Cossa (1995). The amorphous oxyhydroxide fraction of the SPM was extracted on aliquot samples by partial dissolution using ascorbic acid/citric acid (1/2.5 w/w) at $\mathrm{pH} 8$, according to Kostka and Luther (1994). The iron and manganese content of the oxides were measured by atomic absorption spectrometry. Mercury 
was also determined in this fraction $\left(\mathrm{Hg}_{\mathrm{ox}}\right)_{\mathrm{P}}$ using the same method as for $(\mathrm{HgT})_{\mathrm{P}}$. This operationally defined fraction is named herein as the oxyhydroxide fraction. The plankton samples were freeze dried and analysed using a solid mercury analyser (AMA-254 ${ }^{\circledR}$, Altec) and an ethylation method for total mercury and MMHg respectively (Liang et al., 1994; Cossa et al., 2002b). Detection limits, defined as 3.3 times the standard deviation of the blanks, expressed per unit sample analyzed, were $0.2 \mathrm{pM}$ for $(\mathrm{HgR})_{\mathrm{D}}, 0.4 \mathrm{pM}$ for $(\mathrm{HgT})_{\mathrm{D}}, 40 \mathrm{fM}$ for $(\mathrm{MMHg})_{\mathrm{D}}, 20$ pmol.g ${ }^{-1}$ for $(\mathrm{HgT})_{\mathrm{P}}$ and $(\mathrm{MMHg})_{\mathrm{P}}$. The detection limits for plankton analyses were 37 and 10 pmol.g ${ }^{-1}$ (dry weight) for total and MMHg respectively. For all the analyses, precision was less than $10 \%$ (average $5 \%$ ). Method accuracy has been checked using the available reference material (MESS-2 from the National Research Council of Canada and IAEA-142 from the International Atomic Energy Agency).

Salinity measurements used for data plotting were performed on collected water samples using a conductivity probe (Portasal ${ }^{\circledR}$ ). Particulate organic carbon, nitrogen, hydrogen and oxygen concentrations were measured with a CHN analyzer (EA-1110 ${ }^{\circledR}$, ThermoQuest) after filtration of the water samples through glass fiber filters (GF/ $\mathrm{F}^{\circledR}$, Whatmann). Chlorophyll and phaeophytin were determined on glass fiber filters $\left(G F / F^{\circledR}\right.$, Whatmann). Water filtered through GF/F filters was used for the determination of dissolved organic carbon (TOC $5000 \mathrm{~A}^{\circledR}$, Shimadzu), and nutrients. Dissolved oxygen was determined by the standard Winkler method. The C:N ratio was used as an index to estimate the organic maturation of the particles (e.g., Matson and Brinson, 1990; Bodineau et al., 1998): the higher the C:N ratio is, the more the organic particles are mineralized. 


\section{RESULTS}

\subsection{Hydrosedimentary and geochemical settings}

The winter cruise was made under flood conditions while for the summer cruise low flow prevailed (Table 1). The physical and chemical characteristics of the waters throughout the estuary are summarized in figures 2 and 3 for Mercaux-1 (winter) and Mercaux-2 (summer) respectively. In the dissolved phase, the nutrient (data not shown) distributions did not show any strong departure from dilution lines. Other parameters were strongly dependent on the SPM distribution, as expected, given the importance of the particle dynamic in a macro-tidal estuary such as the Seine estuary. Thus, for a better description of the data, we partitioned off the estuary into four compartments depending on SPM load and salinity (Table 2): (i) the head of the estuary (upstream the HTZ), (ii) the HTZ (SPM >100 $\mathrm{mg} \mathrm{l}^{-1}$ ), (iii) the plume (salinities $>25$ and $<32$ PSU) and (iv) the adjacent coastal waters (salinities $>32$ PSU).

The geographical situations, the maximum values of SPM concentrations in the HTZ, and the turbidity gradients through the plume and in the adjacent coastal waters were similar for both cruises (Figs. 2 and 3; Table 2). However, the distribution of the suspended particulate matter (SPM) versus salinity shows a shift of the location of the HTZ as a result of the two distinct river discharges and tidal conditions during the two cruises. According to the distributions of SPM, particulate organic carbon (POC), particulate organic nitrogen (PON), and $\mathrm{C}: \mathrm{N}$ ratios, four major types of particles corresponding to the four previously defined compartments can be distinguished (Table 2).

The prominent feature was the stability and the relatively high organic content of the HTZ particles, whatever the season. The phaeopigment to chlorophyll $a$ ratio (Table 2), which indicates the degree of degradation of chlorophyll pigments, was positively correlated with 
SPM concentrations $(r=0.79, P<0.005)$ and suggests that the HTZ acts as a degradation reactor for the organic material entering the estuary from both riverine and marine sources. This view, which is consistent with biomarker studies on organic matter (Bodineau et al., 1998; Thoumelin et al., 1997), is reinforced by the low $\mathrm{pH}$ values measured within the HTZ (Table 2). Moreover, the degree of oxygen saturation demonstrated that oxic conditions prevailed in winter (84\% - $93 \%$ ) and hypoxic conditions in summer (62 - $68 \%$ ), consistent with an increase of microbial activity in this season. For the whole estuary, the concentrations of chlorophyll $a$ were more than one order of magnitude higher during the summer than during the winter. The high values in summer corresponded to high chlorophyll $a$ and low C:N values (Table 2) and testify to the importance of phytoplankton in the SPM. In additon, the low C:N ratios in both cruises suggest a strong influence of marine particles in the Seine estuary compared to other macrotidal estuaries (Turner et al., 1991).

In order to further characterize the SPM, the iron and manganese of the amorphous oxyhydroxide fraction (ascorbic acid fraction) of particles were determined. Results on table 2 show that (i) the lowest iron and manganese mean concentrations were found in the marine particles, and that (ii), within the HTZ, the mean iron and manganese concentrations, which are positively correlated ( $\mathrm{r}=0.7, P<0.005)$, tended to be higher in summer than in winter, consistent with an oxidation rate promoted by temperature (Yeats and Strain, 1990).

In summary: (i) the HTZ particles were roughly of similar composition whatever the cruise; (ii) the SPM composition in the marine end-member indicated an increasing amount of phytoplankton, which were especially well developed in summer conditions; (iii) the HTZ acts as a degradation reactor for the organic material entering the estuary; and (iv) the amorphous oxyhydroxide fraction of SPM in the HTZ is better developed in the summer.

\subsection{Dissolved mercury}


Total dissolved mercury concentrations $\left((\mathrm{HgT})_{\mathrm{D}}\right)$ varied between $0.8 \mathrm{pM}$ and $4.7 \mathrm{pM}$ within the estuary and showed strong seasonal differences with higher values found in winter at low salinity (Fig. 4 ; Table 2). In the adjacent marine area (> $32 \mathrm{PSU}),(\mathrm{HgT})_{\mathrm{D}}$ concentrations were variable but roughly of the same order in both seasons (winter: $1.3 \pm 0.4$ pM; summer: $1.6 \pm 0.3)$. During the winter cruise, $(\mathrm{HgT})_{\mathrm{D}}$ concentrations decreased from 4.7 to $0.8 \mathrm{pM}$ within the 0 - 5 PSU salinity range suggesting non-conservative mixing behavior. In addition, between 12 and 15 PSU two exceptionally high values of total dissolved mercury were observed. Notably, these particular samples, which were collected at the beginning of the flood period when resuspension was high, also exhibited high values of reactive dissolved and particulate mercury.

The reactive dissolved mercury concentrations $\left((\mathrm{HgR})_{\mathrm{D}}\right)$ varied from 0.21 to $1.33 \mathrm{pM}$ and showed no significant relationship to the salinity (Fig. 5). In the estuarine mixing zone (salinity <32 PSU), $(\mathrm{HgR})_{\mathrm{D}}$ concentrations were clearly higher in winter (mean: $1.1 \pm 0.2 \mathrm{pM}$ ) than in summer (mean: $0.5 \pm 0.2 \mathrm{pM}$ ) (Fig. 5). The lowest $(\mathrm{HgR})_{\mathrm{D}}$ concentrations, observed in summer, corresponded to the highest SPM values. For the adjacent coastal waters (salinities > 32 PSU), reactive mercury concentrations were variable (0.5 - $1.3 \mathrm{pM})$ and displayed exactly the same average and standard deviation in both seasons: $0.8 \pm 0.2 \mathrm{pM}$. In this area and in the plume, the $(\mathrm{HgR})_{\mathrm{D}} /(\mathrm{HgT})_{\mathrm{D}}$ ratio displayed a higher average value in winter $(65 \pm 12 \%)$ than in summer (40 $\pm 8 \%)$. Conversely, the ratio did not show variation with season in the HTZ: $42 \pm 12 \%$ in winter and $38 \pm 12 \%$ in summer. The seasonal differences in the adjacent coastal waters (salinities $>32$ PSU) suggest the potential consumption of $(\mathrm{HgR})_{\mathrm{D}}$ by complexation and/or reduction in summer. The lack of higher concentrations of DOC in summer (Table 2) negates the complexation explanation for the lower $(\mathrm{HgR})_{\mathrm{D}} /(\mathrm{HgT})_{\mathrm{D}}$ ratio observed in summer. 
Dissolved gaseous mercury (DGM) concentrations were relatively low or below the detection limit $(0.08 \mathrm{pM})$ and stable along the estuarine mixing zone (range: $<0.08-0.82$ $\mathrm{pM}$ ) and were less than the detection limit during the summer cruise, which is consistent with the lower solubility of $\mathrm{Hg}^{0}$ when temperature increases. For salinities >32 PSU, DGM concentrations were more variable and displayed higher values (Fig. 5).

Dissolved monomethylmercury $(\mathrm{MMHg})_{\mathrm{D}}$ concentrations were only measured for the Mercaux-2 cruise samples. The values varied between the detection limit of the analytical method (40 fM) and $98 \mathrm{fM}$ for the 24 samples analyzed. This represents on average less than $1.5 \%$ of the $(\mathrm{HgT})_{\mathrm{D}}$. The highest values were found associated with both fresh and marine waters.

\subsection{Particulate mercury}

Total particulate mercury $\left((\mathrm{HgT})_{\mathrm{P}}\right.$, Table 2$)$ in the Seine estuary varied from 0.07 to 3.80 nmol.g $\mathrm{g}^{-1}$ and represented from 35 to $99 \%$ of the total mercury (particulate + dissolved mercury). (HgT) $)_{\mathrm{P}}$ concentrations covaried positively with the suspended particulate matter (Fig. 6).

The data in figure 6 and table 2 show that, in both seasons, the higher values of $(\mathrm{HgT})_{\mathrm{P}}$ were associated with a higher SPM load which corresponded to HTZ particles with high POC and $\mathrm{C}: \mathrm{N}$ values, whereas, the lower values of $(\mathrm{HgT})_{\mathrm{P}}$ were associated with marine particles, which corresponded to a low SPM load. In winter, a significant correlation between (HgT)P and the percentage of POC was observed (Fig. 7). During the summer, the relationship was less significant $(r=0.62)$ as a consequence of the presence of particles with high chlorophyll content and low particulate mercury concentrations (Table 2). This suggests that the summer primary production probably influences the particulate mercury concentrations by diluting the 
Hg enriched particles escaping from the HTZ with phytoplankton of lower mercury concentrations (Table 3).

The $(\mathrm{MMHg})_{\mathrm{P}}$ was measured in a few samples collected during the Mercaux-2 cruise ; the concentration ranged from lower than the limit of detection (10 pmol.g ${ }^{-1}$ to) to 34 pmol.g-1 and represented between 0.05 and $2 \%$ of the total particulate mercury.

The concentrations of particulate mercury within the oxyhydroxide fraction expressed relative to the mass of bulk particles $\left(\left(\mathrm{Hg}_{\mathrm{ox}}\right)_{\mathrm{P}}\right)$ ranged from 0.04 to $0.28 \mathrm{nmol}^{-\mathrm{g}^{-1}}$ and average values tended to be higher in summer $\left(0.16 \pm 0.06 \mathrm{nmol} . \mathrm{g}^{-1}\right)$ than in winter $(0.11 \pm 0.06$ nmol.g ${ }^{-1}$ ) (Table 2). From a few percent (in the HTZ) to more than half (in coastal waters) of total particulate mercury $(\mathrm{HgT})_{\mathrm{P}}$ was associated with the amorphous oxides. Noteworthy are the correlations found between manganese or iron and mercury (Fig. 8). In the case of iron two distinct data sets were identified, one corresponding to summer and the other to winter conditions (Fig. 8); this may be due to higher sorption capacities of the freshly precipitated iron oxyhydroxides in summer.

The exchangeable mercury fraction of the SPM has been estimated by incubating suspended matter sub-samples from the river and the HTZ (collected on LRC Millipore membranes) in fresh and seawater at $20^{\circ} \mathrm{C}$. The variations of the $(\mathrm{HgT})_{\mathrm{D}}$ concentrations were followed after 30, 60, and 90 minutes for one day. In no case did the desorbed fraction exceed $0.2 \%$ of the $(\mathrm{HgT})_{\mathrm{P}}$ (Brevière, 2002).

Total mercury in plankton collected in the plume and seaward ranged from 0.2 and 0.8 nmol.g ${ }^{-1}$ (dry weight) (Table 3); MMHg determined in 6 samples constituted between 3.8 and $18.4 \%$ of the HgT (Table 3). 


\section{DISCUSSION}

\subsection{The removal of "dissolved" mercury in the HTZ}

In estuaries, the type of distribution of a dissolved chemical species against salinity depends of the fluctuation of the inputs and the biogeochemical behaviour of the species. Changing the concentration at the source end-members in a period of time shorter than the mixing time of the water may generate an apparent non-conservative dilution line. On the contrary, when the concentrations at the end-members remain relatively constant, a non-linear dilution line suggests phase exchanges. The rapid decrease of $(\mathrm{HgT})_{\mathrm{D}}$ in the early mixing of the Seine estuary in winter (Fig. 4) may either be due to the removal of dissolved species or to the effect of short term variation of the $(\mathrm{HgT})_{\mathrm{D}}$ concentration at the fresh water end-member. The latter hypothesis is unlikely since the water discharge variations, which are known to change with variations in mercury concentrations (Cossa et al., 2002a), were too small (Table 1) to generate concentration variations of several picomolar amplitude. The $(\mathrm{HgT})_{\mathrm{D}}$ decrease has therefore to be interpreted as a real estuarine removal process. This type of behavior has already been observed for other estuaries when the $(\mathrm{HgT})_{\mathrm{D}}$ riverine concentrations largely exceed those of the marine end-members (Cossa et al., 1988; Leermakers et al., 1995; Guentzel et al., 1996). Two complementary mechanisms are usually cited to explain this observation: the adsorption of the dissolved metal onto particles in the HTZ and the flocculation of organic colloids, with the possible transfer of dissolved species to large aggregates via colloidal intermediates (e.g., Boyle et al., 1977; Honeyman and Santschi, 1989; Santschi et al., 1997; Wen et al., 1999). 
Interestingly, in the Seine estuary, the removal does not appear to involve the "reactivedissolved" mercury species (Fig. 5), but the "non-reactive dissolved" mercury $\left[(\mathrm{HgNR})_{\mathrm{D}}\right.$, calculated as the difference between $(\mathrm{HgT})_{\mathrm{D}}$ and $\left.(\mathrm{HgR})_{\mathrm{D}}\right]$ (Fig. 9). The $(\mathrm{HgNR})_{\mathrm{D}}$ concentrations were positively correlated with the dissolved organic carbon in winter $(\mathrm{r}=$ 0.83, $P<0.005$ ) (Fig. 10) supporting the hypothesis of an organic mercury association in that fraction, as observed by Stordal et al. (1996) for three Texas estuaries. Turner et al. (2001) recently proposed that the salting out of $\mathrm{Hg}(\mathrm{II})$-organic complexes explains the increase in the mercury distribution coefficients $\left(\mathrm{K}_{\mathrm{D}}\right)$ with the increasing salinity that they experimentally observed in three U.K. estuaries. The mercury $K_{D}$ in the Seine estuary follows a more complex relationship with salinity (Fig. 11a) due at least in part to the nature of the organic matter (Fig. 11b). In addition, Stordal et al. (1996) showed that from 12 to $93 \%$ of the total operationally defined "dissolved" mercury was associated with colloidal particles (0.45 $\mu \mathrm{m}$ to $1 \mathrm{kDa}$ ). Since the input of dissolved mercury from the pore water of the sediments is insufficient to explain a concentration increase in the water column (from data of Mikac et al., 1999), the positive correlation between $(\mathrm{HgNR})_{\mathrm{D}}$ and SPM concentrations in the mixing zone of the Seine estuary in winter $(r=0.56, P<0.01)$ suggests that this mercury fraction is partially constituted by colloidal material. Thus, the most likely mechanisms for the observed removing of so-called "dissolved" mercury in the HTZ of the Seine estuary is the sorption of truly dissolved organic mercury associations and the flocculation of organic rich colloidal material favored by the increasing collision of material within this high suspended load environment.

\subsection{Mercury, organic matter and plankton}

The dissolved and particulate organic matter including phytoplankton have been shown to control mercury distribution in estuarine environments (e.g., Coquery et al., 1995; Benoit et 
al., 1998). The positive correlation found between $(\mathrm{HgT})_{\mathrm{P}}$ and POC (Fig. 7) shows that increasing the particulate organic material tends to favor the partition of mercury toward the particulate form in winter (Fig. 11a). In summer, the relationship between $(\mathrm{HgT})_{\mathrm{P}}$ and POC (Fig. 7) is less significant ( $\mathrm{r}=0.42, P<0.05)$ than in winter $(\mathrm{r}=0.87, P<0.005)$ suggesting different nature and sources of organic matter, testified to by the high nitrogen and chlorophyll $a$ contents in summer (Table 2). In the summer, phytoplanktonic blooms bring "fresh" organic matter (low C:N ratio) to the system and act as a dilution effect for particulate mercury concentrations with a consequent effect on $K_{D}$ relationships (Fig. 11b). Indeed, the phytoplankton collected on nets indicate that their Hg concentrations are lower than those of the particles collected on membrane filters (Table 3). Mercury tends to be enriched in maturated organic particles (with high C:N and Phae:Chlora ratios) compared to fresh organic matter, typically represented by plankton (with low C:N and Phae:Chlora ratios) (Fig. 12). The increase of complexation with functional groups during the organic degradation is a potential explanation for this observation. It is well known that humic material (high C:N ratio, Rostad et al., 1997) presents a very strong complexing capacity for many metals, including mercury (e.g., Weber, 1988). With the winter high precipitation, large amounts of dissolved, colloidal humic substances reach the Seine river from soil weathering (Bodineau et al., 1998).

\subsection{Mercury enrichment in the HTZ}

Particulate mercury concentrations were found to increase with SPM concentration (Fig. 6). Its distribution could be defined in terms of the mixing of different sources of particles as well as in terms of the nature of the SPM. This behaviour is well explained by a dilution model as proposed by Turner and Millward (2000) for metals in the Humber and Thames estuaries. A slow settling low metal particle population with relatively invariant turbidity is 
augmented (diluted) by a variable amount of higher metal content particles derived from the resuspension which results in the HTZ formation. The dilution model for mercury in the HTZ of the Seine estuary is: $(\operatorname{HgT})_{\mathrm{P}}=1.87-13.08 / \mathrm{SPM}\left(\right.$ Fig. 6), with $(\mathrm{HgT})_{\mathrm{P}}$ in nmol.g ${ }^{-1}$ and SPM in mg. l $^{-1}$. In this model, the end-members of particles are the slow settling fine particles found at the head of the estuary and in the plume, which have a low mercury content and the resuspended population, which constitutes the resident particle load of the HTZ and is mercury enriched. The "plateau" of the $(\mathrm{HgT})_{\mathrm{P}}-\mathrm{SPM}$ relationship reaches a threshold between 2 and 4 nmol.g ${ }^{-1}$ (Fig. 6), a concentration which is in the typical mercury concentration range of the HTZ and sediment particles (Mikac et al., 1999). This is consistent with the idea that the HTZ is fed by deposited sediments. This raises the question: Which mechanisms are responsible for this enrichment and how does the particle sorting redistribute mercury seaward?

There is no registered mercury source known in this part of the estuary; industrial inputs exist, but upstream at the head of the estuary (Cossa et al., 2002a) which may account for the mercury enrichment in the HTZ particles. On the other hand, our results demonstrate that in the Seine estuary, mercury is enriched on mature organic particulate matter (Fig. 12) and on amorphous oxyhydroxides as the ratio of $(\mathrm{Hg})_{\mathrm{ox}}$ increases with SPM (Fig. 13). Since the oxyhydroxide fraction is operationally defined, it cannot be precluded that part of the organic matter may also be mobilized during the ascorbic acid digestion. Thus, the mercury binding to particulate should be governed by the competition between oxides, DOC and POC, from which ternary complexes may result, since, according to Benoit et al. (2001), the binding constant of mercury to iron oxides is insufficient to out compete binding to DOC in solution. In addition, metals sulfide precipitation is more than likely an other mechanism for mercury enrichment in the particulate phase. Herta-Diaz et al. (1996) proposed that coprecipitation (e.g., $\mathrm{FeS} / \mathrm{Hg} / \mathrm{HgS}$ ) is a possible mechanism to immobilize mercury in anoxic sediments. 
Mikac et al. (1999) have shown that, in the sulfidic sediment below the HTZ area, particulate mercury concentrations vary from 2 to $4 \mathrm{nmol.g}{ }^{-1}$, i.e., the level of the highest $\mathrm{Hg}$ concentration in the HTZ (Fig. 6).

In a macrotidal estuary like the Seine, the HTZ is very dynamic with the SPM load being fed or impoverished by particles from sediment as the energy in the water increases or decreases as a result of the succession of flood and ebb. The succession of sedimentation and resuspension phases leads to the periodic injection into the HTZ of surface and subsurface sedimentary particles. In the Seine estuary the oxycline is within a few centimeters of the sediment surface and thus the surface layers are enriched in oxyhydroxides and the subsurface with iron monosulfide (Boust et al., 2000).

Mercury reaches the estuary mainly associated with the riverine and marine particles, including organic matter and oxyhydroxides, which are temporarily trapped in the HTZ and mixed with autochthonous HTZ particles. The largest particles are periodically settled, undergoing diagenetic reactions and resuspendsion. The high C:N and Phae:Chlora ratios (Table 2) suggest that a part of the POC is mineralized in the HTZ and/or in the surficial sediment underlying the HTZ. Organic degradation of SPM has been shown to mobilize mercury at the benthic interface (nepheloid layer and subsurface porewater of the sediment) in the St. Lawrence estuary (Cossa and Gobeil, 2000). According to these authors, this mercury fraction is quickly readsorbed onto particles. Many functional groups of the refractory organic matter and mineral solids are candidates for supporting the readsorption: thiol, hydroxyl, carboxyl, etc. ; coprecipitation is another possible mechanism ("FeS/Hg/HgS") (e.g., HuertaDiaz et al., 1996). In certain parts of the estuary where net sedimentation may exist, the "FeS/Hg/HgS" fraction is probably buried and trapped.

In brief, the maturation of organic matter (attested by the positive relationship between $(\mathrm{HgT})_{\mathrm{P}}$ and Phae:Chlora, $\mathrm{r}=0.84, P<0.005$ and C:N, Fig. 12), oxyhydroxides (Fig. 13) and 
sulfides precipitation (Fig. 8 ; Mikac et al., 1999) favor the mercury enrichment of particles. The early diagenetic reactions at the benthic interface are likely responsible for these processes, and the long residence time of particles in the HTZ of the Seine estuary (up to 500 days according to Thouvenin et al., 1999) favors the reactions. According to the hydrodynamic conditions mercury escapes seaward as fine particulate and colloidal material within the plume, partially associated with the oxyhydroxides. Indeed, this fraction corresponded to less than $10 \%$ of the total mercury present in HTZ, whereas it is higher in the plume and up to $50 \%$ seaward.

\subsection{Thermodynamics and kinetics : a modeling attempt}

The Hg speciation has been simulated using a surface COmplexation MOdel : MOCO (Gonzalez et al., 2001a; Thouvenin et al., 1997), which is based on surface complexation theory and where dissolved species are calculated from the chemical equilibrium between metal and dissolved ligands as proposed by Stumm et al. (1980), Westall (1987), and Dzombak and Morel (1990). MOCO has been tested and validated for cadmium, cesium and cobalt in three French estuaries: Seine, Loire and Gironde (Gonzalez et al., 2001a and b; 2002). The concentrations of different variables required by the model to simulate $\mathrm{Hg}$ speciation are those of dissolved ligands (Appendix A) and suspended matter. MOCO allows for different types of particles (oxyhydroxides, clay, and organic material) (i) either as single sorbent phases treated individually, or (ii) as natural particles taken as a global sorbent phase. In this study, particles are treated as a global sorbent phase but not all of the mercury in particles is considered exchangeable. In this approach, the "global" adsorption properties of particles are represented by a set of surface complexation parameters (Appendix B) that were estimated independently (without fitting of the data with the model). The Hg adsorption is modeled by the reaction: 


$$
-\mathrm{SOH}+\mathrm{Hg}^{2+}=-\mathrm{SOHg}^{+}+\mathrm{H}^{+} \quad \text { (where }-\mathrm{SOH} \text { is a neutral surface site) }
$$

The model calculates the surface sites speciation as a function of the acido-basic properties of the particles and the surface sites concentration $\left(\sum \mathrm{SOH}=-\mathrm{SOH}_{2}{ }^{+}+-\mathrm{SOH}+-\mathrm{SO}^{-}\right.$ ). The quantity of available $\mathrm{Hg}^{2+}$ for the adsorption is controlled by the concentration of the various dissolved ligands taken into account by the model (Appendix A), and their concentration is a function of the salinity and the $\mathrm{pH}$.

As most of the parameters linked to the sorption properties of natural particles cannot be measured directly, their evaluation required a variety of experimental approaches (Gonzalez et al, 1998; 2001a) applied to particle samples taken throughout the estuaries. The parameters used by the model (Appendix B) are as follows: (i) the specific surface area of the particles (in $\mathrm{m}^{2} \cdot \mathrm{g}^{-1}$ ), measured via nitrogen adsorption using the BET method (COULTER SA 3100); (ii) the total concentration of surface exchangeable sites of protons (in mol.g ${ }^{-1}$ of SPM) evaluated by potentiometric acid-base titration (ABT); (iii) the mean intrinsic surface acido-basic constants of these sites $\left(\mathrm{K}_{\mathrm{a} 1}\right.$ and $\left.\mathrm{K}_{\mathrm{a} 2}\right)$, determined via adjustment of the experimental data obtained by ABT using FITEQL 3.2 (Gulmini et al, 1996; Westall, 1982); (iv) the global intrinsic complexation constant of these sites with regard to $\mathrm{Hg}$ and (v) the exchangeable particulate fraction.

Due to the rough evaluation of these parameters and their natural variability within the estuary, we carried out simulations with sets of minimal, mean and maximum values. On the basis of these data, the model distributes the total measured mercury (minus the non exchangeable particulate fraction) among the different considered species (sorbed $\mathrm{Hg}$ and dissolved species: $\mathrm{Hg}^{2+}$, chloride, hydroxide, sulfate, bromide and thiol complexes). For each field measurement point, a system of non-linear equations is solved (balance of mass, charges, and surface sites with electrostatic effect correction) to calculate concentrations of the various species at equilibrium. To facilitate comparison of the simulations with field measurements, 
model results are given as "reactive dissolved $\mathrm{Hg} "\left(\mathrm{HgR}_{\mathrm{D}}=\right.$ sum of the various calculated inorganic dissolved species, see Appendix A), "non reactive dissolved mercury" $\left(\mathrm{HgNR}_{\mathrm{D}}=\right.$ thiol complexes) and particulate Hg (calculated adsorbed + non-exchangeable, see Appendix B).

A good estimation of the measured total dissolved mercury was obtained with the minimum values of the surface complexation parameters and by considering $0.05 \%$ of the particulate to be exchangeable mercury, as determined experimentally (Appendix B). The correlations between measured and calculated $(\mathrm{HgT})_{\mathrm{D}}$ concentration are $\mathrm{r}=0.98(P<0.001)$ and $\mathrm{r}=0.85(P<0.001)$ for winter and summer respectively (Fig. 14a). Upstream and downstream of the HTZ, the model predicts quite precisely the mercury partitioning. The differences found for samples from the HTZ, that is, overestimation of the dissolved fraction (Fig. 14b), could be due to an inexact evaluation of the mercury mobile fraction of the HTZ particles or poor accuracy of some model parameters (specific surface, site density, complexation constant, etc.) or due to the lack of equilibrium in the field.

The predicted speciation in the dissolved phase, as shown by the $\operatorname{HgR}_{\mathrm{D}} / \mathrm{HgT}_{\mathrm{D}}$ ratios (Fig. 15b), does not fit with the measurements. For salinities higher than 13 PSU, the model calculates that the reactive mercury species should correspond to 93 to $100 \%$ of the total mercury, while according to our measurements, this fraction was only $62 \pm 13$ and $41 \pm 7 \%$ for this same salinity range, in winter and in summer respectively (Fig. 15). The dominance of the reactive species with an increase of salinity has already been pointed out by previous models (e.g., Morel, 1983) and is commonly attributed to the formation of mercury chlorocomplexes. In accordance with previous studies concerning the Seine river estuary and bay (Coquery et al., 1997; Cossa et al., 2002a), we reported significant concentrations of non reactive mercury even in seawater. To test the hypothesis of the role of strong dissolved ligand we increased by 100 times the concentrations of dissolved thiols in the model, but the 
results displayed by the calculation still show a quasi-absence of non reactive mercury (Fig. 15b). Different explanations can be proposed to explain this difference: (i) an underestimation of the reactive fraction due to the analytical methods; (ii) an overvaluation of the complexation constants for the chlorocomplexes, both hypotheses which seem unlikely, or (iii) the presence of an unknown strong dissolved ligand which would "shift" the thermodynamic equilibrium in favour of non reactive mercury species.

In addition, to thermodynamic equilibria, the distribution of "dissolved" mercury species are driven by the kinetics of reaction, mainly $\mathrm{Hg}(\mathrm{II})$ reduction and methylation, and the kinetics of mercury adsorption and desorption from particles. The methylation does not seem to drive a large proportion of the mercury present in the estuary. On the contrary, mercury reduction is quantitatively a major process in the Bay of Seine (Cossa et al., 2002a). Indeed, the high variability in $(\mathrm{HgR})_{\mathrm{D}}$ concentrations is parallel with high variability in the DGM species : the two parameters covary with a correlation coefficient of $0.94(P<0.005)$. DGM, mostly composed of $\mathrm{Hg}^{0}$, results from the reduction of $(\mathrm{HgR})_{\mathrm{D}}$, mostly composed of inorganic $\mathrm{Hg}(\mathrm{II})$ species. Thus, the observed deficiency in $(\mathrm{HgR})_{\mathrm{D}}$ in summer, compared to winter seems to be the result of the enhanced reduction by both photochemical and biological activities. Photoreduction in the coastal seawater is enhanced in summer which leads to a higher production and atmospheric evasion of DGM (more than $20 \%$ of the total mercury brought by the Seine river according to Cossa et al., 2002a) and could cause a consecutive decrease in reactive mercury concentrations. It may be speculated that the mercury association with the oxyhydroxide fraction found in the Seine Bay may also enhance the availability of Hg(II) for reduction through photochemical mechanisms involving the Fe(II) / Fe(III) couple (Zhang et Lindberg, 2001). 
Acknowledgements—Support has been provided by an Agence de l'Eau Seine Normandie grant (Déléguation d'Honfleur) and the Seine-Aval Program grants. Thanks are due to J. Bretaudeau, C. Beucher, I. Truquet, and the Laboratoire de Géochimie des Eaux team for their participation in sampling and analyses. Thanks are also due to Captain Fontaine of the R/V Thalia and his crew. We are grateful to R.P. Mason and W. Delor for comments on the manuscript and the editing respectively. 


\section{REFERENCES}

Benoit J. M., Gilmour C.C., Mason R.P., Riedel G.S., and Riedel G.F. (1998) Behavior of mercury in the Patuxent River Estuary. Biogeochemistry 40, 249-265.

Benoit J. M., Mason R.P., Gilmour, C.C., and Aiken, G. R. (2001) Constants for mercury binding by dissolved organic matter isolated from the Florida Everglades. Geochim. Cosmochim. Acta, 65, 4445-4451.

Bloom N. and Fitzgerald W.F. (1988) Determination of volatile mercury species at the picogram level by low temperature gas chromatography with cold-vapour atomic fluorescence detection. Anal. Chim. Acta. 208, 151-161.

Bodineau L., Thoumelin G., Béghin V., and Wartel, M. (1998) Tidal time scale changes in the composition of particulate organic matter within the estuarine turbidity maximum zone in the macrotidal Seine estuary, France: the use of fatty acid and sterol biomarkers. Estuar. Cstl. Shelf Sci. 47, 37-49.

Boust D., Fischer J.C., Oudanne B., Petit F., and Wartel, M. (2000) Le fer et le manganese: réactivités et recyclages. Rapport du Programme scientifique Seine-Aval $N^{\circ} 9$. Editions IFREMER, Plouzané, France. ISBN 2-84433-028-2, 39pp.

Boyle E. V., Edmond J. M., and Sholkovitz, E. R. (1977) The mechanism of iron removal in estuaries. Geochim. Cosmochim. Acta. 41, 1313-1324.

Brenon I. and Le Hir P.(1999) Modelling the Turbidity Maximum in the Seine Estuary (France): Identification of Formation Processes. Est. Cstl. Shelf Sci. 49, 525-544.

Brevière, E. (2002) Cinétique de sorption du mercure sur des particules marines. Rapport de stage Ecole Nationale Supérieure de Chimie de Mulhouse / IFREMER. Juillet 2002.26p 
Département Polluants chimique, IFREMER, F.44311 Nantes cedex, France. Unpublished manuscript.

Coquery M., Cossa D., and Martin J.M., (1995) The Distribution of Dissolved and Particulate Mercury in Three Siberian Estuaries and Adjacent Arctic Coastal Waters. Water, Air, Soil Pollut. 80, 653-664.

Coquery M.D., Cossa D., and Sanjuan J. (1997) Speciation and Sorption of Mercury in Two Macro-Tidal Estuaries. Mar. Chem. 58, 213-227.

Cossa D. and Gobeil C. (2000) Mercury speciation in the lower St. Lawrence Estuary. Can. J. Fish. Aquat. Sci. 57, 1-10.

Cossa D., Gobeil C., and Courau P. (1988) Dissolved Mercury Behavior in the St. Lawrence Estuary. Estuar. Cstl. Shelf Sci. 26, 227-230.

Cossa D., Coquery M., Gobeil C., and Martin J. M. (1996) Mercury fluxes at the ocean margins. In: Global and Regional Mercury cycles: Sources, Fluxes and Mass Balances. Baeyens W.; Edbinghaus R., Vasiliev O. (Eds.) Kluwer , Dordrech, pp. 229-247.

Cossa D., Laurier F. J. G., and Ficht A. (2002a) Mercury contamination in the Seine basin and estuary, France: An overview. In: Biogeochemistry of Environmentally Important Elements. Yong Cai and Olin C. Braids editors. American Chemical Society, 432pp.

Cossa D., Coquery M., Naklé K. and Claisse D. (2002b) Dosage du mercure total et du monométhylmercure dans les organismes et les sédiments marins. Méthodes d'analyses en milieu marin. Collection du Ministère de l'Ecologie et du Développement Durable et IFREMER. 27 p. ISBN 2-84433-105-X. Edition IFREMER, Plouzané, France.

Dyrssen D. (1988) Sulfide complexation in surface seawater. Mar. Chem. 24, 143-153. 
Dyrssen D. and Wedborg W. (1991) The sulphur-mercury (II) system in natural waters. Water Air Soil Pollut. 56, 507-519.

Dzombak D.A. and Morel F.M.M. (1990) Surface Complexation Modeling: Hydrous ferric oxide. John Wiley, New-York. 393 p.

Fitzgerald W.F. and Mason R.P. (1997) Biogeochemical Cycling of Mercury in the Marine Environment. P. 53-111. In: Metal ions in biological systems. Vol 34 Mercury and its effects on environmentant and biology. Sigel A and Sigel H. editors.Marcel Dekker, New-York, 604pp.

Gagnon C., Pelletier E., Mucci A., and Fitzgerald W. F. (1996) Diagenetic behavior of methylmercury in organic-rich coastal sediments. Limnol. Oceanogr. 41, 428-434.

Gobeil C. and Cossa D. (1993) Mercury in Sediments and Sediment Pore Water in the Laurentian Trough. Can. J. Fish. Aquat. Sci., 50, 1794-1800.

Gonzalez J.-L., Dange C., and Thouvenin B. (2002) Contribution of modeling to the knowledge of trace elements behaviour and speciation in estuaries. Radioprotection Special issue on "The radioecology-ecotoxicology of continental and estuarine environments”, 37-C1, 743-747.

Gonzalez J.-L., Thouvenin B., Dange C., Fiandrino A., and Chiffoleau, J.-F. (2001a). Modeling of Cd speciation and dynamics in the Seine estuary (France). Estuaries 24, 1041-1055.

Gonzalez, J.-L., Dange, C., Boutier, B., Thouvenin, B. Auger, D. and Chartier, E. (2001b) Modélisation de la spéciation du cadmium dans l'estuaire de la Gironde. In: L'Océanographie du Golfe de Gascogne. D'Elbée, J. and Prouzet, P. editors. Acte de colloques Nº 31. IfREMER, Plouzané, France. ISSN 0761-3962. pp.283-288. 
Guentzel J. L., Powel R. T., Landing W. M., and Mason R. P. (1996) Mercury associated with colloidal material in an estuarine and an open ocean environment. Mar. Chem. 55, $177-$ 188.

Gulmini M., Zelano V., Daniele, P.G., Prenesti E., and Ostacoli G. (1996) Acid-base properties of a river sediment: potentiometric titrations. Anal. Chim. Acta 329, 33-39.

Honeyman B. D. and Santschi P. H. (1989) A brownian-pumping model for oceanic trace metal scavenging: Evidence from Th isotope. J. Mar. Res. 47, 951-992.

Huerta-Diaz M., Tessier A., and Carrigan R. (1996) Geochemistry of trace metals associated with iron monosulphides and pyrite in organic freshwater sediment. Environ. Sci. Technol. 72, 2367-2372.

Kostka J. E. and Luther G. W. (1994) Partitioning and speciation of solid phase iron in saltmarsh sediment. Geochim. Cosmochim. Acta 58, 1701-1710.

Leermakers M., Meuleman C., and Baeyens W. (1995) Mercury speciation in the Scheldt estuary. Water Air Soil Pollut. 80, 641-652.

Le Hir P., Ficht A., Jacinto R. S., Lesueur P., Dupont J.-P., Lafitte R., Brenon I., Thouvenin B. and Cugier P. (2001) Fine Sediment Transport and Accumulations at the Mouth of the Seine Estuary (France). Estuaires 24, 950-963.

Le Roux S.M., Turner A., Millward G.E., Ebdon L., and Apriou P. (2001) Partitioning of mercury onto suspended sediments in estuaries. J. Environ. Monit. 3, 37-42.

Liang L., Horvat M., Bloom N. (1994) An improved speciation method for mercury by GC/CVAFS after aqueous phase ethylation and room temperature precollection. Talanta 41, 371-379. 
Mason, R. P. and Sheu, G.-R. (2002) The Role of Ocean in the Global Mercury Cycle. Global Biogeochemical Cycles 16, xx-xx.

Matson E.A., and Brinson M.M. (1990) Stable carbon isotopes and C:N ratio in estuaries of the Pamlico and Neuse Rivers, North Carolina. Limnol. Oceanogr. 35, 1290-1300.

Mikac N., Niessen S., Oudane B., and Wartel, M. (1999) Speciation of Mercury in sediments of the Seine estuary (France). Appl. Organometal. Chem. 13, 1-11.

Millero F. J. (1991) Composition of the Major Components of Seawater. In: Chemical Oceanography. Second Edition. CRC Press. 469 p.

Morel F.M.M. (1983) Principle of Aquatic Chemistry. J.P. Wiley \& Sons. 446 p.

Quémerais B. and Cossa D. (1995) Protocoles d'échantillonnage et d'analyse du mercure dans les eaux naturelles. Environnement Canada - région du Québec, Conservation de l'environnement, Centre Saint-Laurent. Rapport scientifique et technique ST-31, 39 p.

Rostad C. E., Leenheer J. A. and Daniel S. R. (1997) Organic Carbon and Nitrogen Content Associated with Colloids and Suspended Particulates from the Mississipi River and Some of Its Tributaries. Environ. Sci. Technol. 31, 3218-3225

Santschi P. H., Lenhart J. J., and Honeyman B. D. (1997) Heterogeneous processes affecting trace contaminant distribution in estuaries: The role of natural organic matter. Mar. Chem. 58, 99-125.

Stordal M. C., Gill G. A., Wen L. S., and Santchi P. H. (1996) Mercury phase speciation in surface water of three Texas estuaries: Importance of colloidal forms. Limnol. Oceanogr. 41, 52-61.

Stumm W., Diem D., and Giovanoli R. (1980) Chemistry of manganese in natural waters. Thalassia Jugosl. 16: 177-180. 
Tang, D., Wen L.-S., and Santschi P. H. (2000a) Analysis of biogenic thiols in natural samples by HPLC separation and fluorescence detection with ammonium 7-fluorobenzo2-oxa-1,3-diazole-4-sulfonate (SBD-F). Anal. Chim. Acta 408, 299-307.

Tang, D., Santschi, P. H., Hung C.-C., and Warnken K. (2000b) The distribution of biogenic thiols in surface waters of Galveston Bay. Limnol. Oceanogr. 45, 1289-1297.

Thoumelin G., Bodineau L., and Wartel, M; (1997) Origin and transport of organic matter across the Seine estuary: Fatty acid and sterol variations. Mar. Chem. 58, 59-71.

Thouvenin B., Gonzalez J. L., and Boutier B. (1997) Modelling of pollutants behaviour in estuaries. Mar. Chem. 58, 147-161.

Thouvenin B., Billen G., Even S., Fischer J.C., Gonzalez J.L., Le Hir P., Loizeau V., Mouchel J.M., Olivier C. and Jacinto S.R. (1999) Les modèles: outils de connaissance et de gestion. Fascicule Seine-Aval Nº 16, Editon Ifremer, Plouzané, France. 32 p.

Tseng C.M., de Diego A., Pinay H., Amouroux D. and Donard O.F.X. (1998) Cryofocusing coupled to atomic absorption spectrometry for rapid and simple mercury speciation in environmental matrices. J. Anal. Atom. Spectr. 13, 755-764.

Turner A., and Millward G.E. (2000) Particle Dynamics and Trace Metal Reactivity in Estuarine Plumes. Est. Cstl. Shelf Sci. 50, 761-774.

Turner A., Millward G.E. and Morris A.W. (1991) Particulate Metals in Five Major North Sea Estuaries. Est. Cstl. Shelf Sci. 32, 325-346.

Turner A., Millward G.E., and Le Roux S.M. (2001) Sediment-Water Partitioning of Inorganic Mercury in Estuaries. Environ. Sci. Technol. 35, 4648-4654. 
Weber J. H. (1988) Binding and Transport of Metals by Humic Materials. In: Humic Substances and Their Role in the Environment. F.H. Frimmel and R.F. Christman J. (Eds.), Wiley-Interscience, New-York. 370 p.

Wen L.-S., Santchi P., Gill G., and Paternostro C. (1999) Estuarine trace metal distribution in Galveston Bay: importance of colloidal forms in the speciation of the dissolved phase. Mar. Chem. 63, 185-212.

Westall J. C. (1982). FITEQL - A computer program for determination of chemical equilibrium constants from experimental data. Dep. of Chemistry Rep. 82-01. Oregon State University, Corvallis.

Westall J. C. (1987) Adsorption Mechanisms in Aquatic Chemistry. In : Aquatic Surface Chemistry, W. Stumm (Ed.), Wiley-Interscience, New-York.

Yeats P.A. and Strain P.M. (1990) The oxidation of Manganese in Seawater: Rate Constants Based on Field Data. Est. Cstl. Shelf Sci. 31, 11-24.

Zhang H. and Lindberg S.E. (2001) Sunlight and Iron(III)-Induced Photochemical Production of Dissolved Gaseous Mercury in Freshwater. Environ. Sci. Technol. 35, 928-935. 


\section{TABLES}

Table 1: Hydrodynamic conditions in the Seine bay during the two sampling cruises.* The given water discharges refer to the records at Poses, the last dam before entering the estuary, three days before the beginning and the end of each cruise.

\begin{tabular}{lccc} 
Cruise & Date & Water discharge* & Tide coefficient \\
\hline Mercaux-1 (winter) & 6-13 February 2000 & 755-913 $\mathrm{m}^{3} \mathrm{~s}^{-1}$ (flood) & $52-87$ \\
Mercaux-2 (summer) & 24-31 August 2000 & 404-466 $\mathrm{m}^{3} \mathrm{~s}^{-1}$ (low flow) & 47-108 \\
\hline
\end{tabular}


Table 2. Averages and standard deviations for chemical parameters. HTZ: High turbidity zone ; nd: non determined ; SPM: Suspended particulate matter ; POC: Particulate organic carbon ; PON:

Particulate organic nitrogen ; Chlor $r_{a}$ : Chlorophyll a ; Phaeo: Phaephytin ; DOC: Dissolved organic carbon; $\mathrm{Fe}_{\mathrm{ox}}, \mathrm{Mn}_{\mathrm{ox}}: \mathrm{Hg}_{\mathrm{ox}}$ : Iron, manganese and mercury associated with the amorphous oxide fraction extracted with ascorbic acid (see materials and methods).

\begin{tabular}{|c|c|c|c|c|c|}
\hline & $\begin{array}{c}\text { Water } \\
\text { discharge } \\
\text { (season) }\end{array}$ & $\begin{array}{l}\text { Head of the } \\
\text { estuary }\end{array}$ & HTZ & Plume & $\begin{array}{l}\text { Adjacent coastal } \\
\text { waters }\end{array}$ \\
\hline \multirow[t]{2}{*}{ Salinity (PSU) } & High (winter) & nd & $0.2-24.9$ & $25-32$ & $>32$ \\
\hline & Low (summer) & $0.2-5.0$ & $5.8-24.9$ & $25-32$ & $>32$ \\
\hline \multirow[t]{2}{*}{$\operatorname{SPM}\left(\mathrm{mg} \mathrm{l}^{-1}\right)$} & High (winter) & nd & $378 \pm 234 \quad(n=14)$ & $22 \pm 12(n=10)$ & $11 \pm 2(n=12)$ \\
\hline & Low (summer) & $31 \pm 10 \quad(n=5)$ & $463 \pm 264(n=8)$ & $34 \pm 25(n=10)$ & $7 \pm 2(\mathrm{n}=12)$ \\
\hline \multirow[t]{2}{*}{ POC (\% of SPM) } & High (winter) & nd & $3.0 \pm 0.7 \quad(n=12)$ & $1.2 \pm 0.5(\mathrm{n}=9)$ & $0.4 \pm 0.2 \quad(n=12)$ \\
\hline & Low (summer) & $3.5 \pm 0.2 \quad(n=5)$ & $3.1 \pm 0.3(n=8)$ & $4.5 \pm 3.5(n=9)$ & $2.0 \pm 1.0 \quad(n=12)$ \\
\hline \multirow[t]{2}{*}{ PON (\% of SPM) } & High (winter) & nd & $0.41 \pm 0.08 \quad(n=12)$ & $0.22 \pm 0.16 \quad(\mathrm{n}=9)$ & $0.11 \pm 0.12 \quad(n=12)$ \\
\hline & Low (summer) & $\begin{array}{c}0.53 \pm 0.04 \\
\quad(n=5)\end{array}$ & $0.36 \pm 0.04 \quad(\mathrm{n}=8)$ & $0.68 \pm 0.46 \quad(n=9)$ & $0.33 \pm 0.11 \quad(n=12)$ \\
\hline \multirow[t]{2}{*}{$\mathrm{C}: \mathrm{N}$} & High (winter) & nd & $7.2 \pm 0.7 \quad(n=12)$ & $6.2 \pm 1.1 \quad(n=9)$ & $5.7 \pm 1.1 \quad(n=12)$ \\
\hline & Low (summer) & $6.6 \pm 0.2 \quad(n=5)$ & $8.5 \pm 0.4(n=8)$ & $6.4 \pm 1.0 \quad(n=9)$ & $5.8 \pm 1.1 \quad(n=12)$ \\
\hline \multirow{2}{*}{$\begin{array}{l}\text { Chlor }_{a}(\% \text { oo of } \\
\text { SPM) }\end{array}$} & High (winter) & nd & $0.01 \pm 0.01 \quad(n=14)$ & $0.04 \pm 0.02 \quad(\mathrm{n}=9)$ & $0.05 \pm 0.01 \quad(n=12)$ \\
\hline & Low (summer) & $\begin{array}{c}0.50 \pm 0.45 \\
\quad(n=5)\end{array}$ & $0.04 \pm 0.03 \quad(\mathrm{n}=8)$ & $0.48 \pm 0.60 \quad(n=10)$ & $0.44 \pm 0.43 \quad(n=12)$ \\
\hline \multirow[t]{2}{*}{ Phaeo : Chlor $_{a}$} & High (winter) & nd & $4.8 \pm 1.4 \quad(n=14)$ & $1.3 \pm 0.3(\mathrm{n}=9)$ & $0.7 \pm 0.2 \quad(\mathrm{n}=12)$ \\
\hline & Low (summer) & $0.4 \pm 0.1 \quad(n=5)$ & $2.8 \pm 0.6 \quad(n=8)$ & $0.7 \pm 0.5 \quad(n=10)$ & $0.4 \pm 0.1 \quad(n=12)$ \\
\hline \multirow[t]{2}{*}{ DOC $\left(\mathrm{mg} \mathrm{l}^{-1}\right)$} & High (winter) & nd & $2.3 \pm 0.4 \quad(n=14)$ & $1.1 \pm 0.2(\mathrm{n}=9)$ & $1.1 \pm 0.1 \quad(\mathrm{n}=12)$ \\
\hline & Low (summer) & $2.5 \pm 0.1 \quad(n=5)$ & $2.2 \pm 0.2(\mathrm{n}=8)$ & $1.6 \pm 0.2(\mathrm{n}=10)$ & $1.1 \pm 0.2(\mathrm{n}=12)$ \\
\hline \multirow[t]{2}{*}{$\mathrm{pH}$} & High (winter) & nd & $7.95 \pm 0.06 \quad(n=14)$ & $8.08 \pm 0.02 \quad(n=10)$ & nd \\
\hline & Low (summer) & $\begin{array}{c}8.03 \pm 0.07 \\
\quad(n=5)\end{array}$ & $7.89 \pm 0.05 \quad(n=8)$ & $8.20 \pm 0.15 \quad(n=10)$ & $8.23 \pm 0.05 \quad(n=12)$ \\
\hline \multirow[t]{2}{*}{$(\mathrm{HgT})_{\mathrm{D}}(\mathrm{pM})$} & High (winter) & nd & $2.75 \pm 1.10 \quad(n=14)$ & $1.04 \pm 0.13(\mathrm{n}=9)$ & $1.35 \pm 0.39(\mathrm{n}=12)$ \\
\hline & Low (summer) & $1.32 \pm 0.04(\mathrm{n}=5)$ & $1.34 \pm 0.12(\mathrm{n}=8)$ & $1.70 \pm 0.17 \quad(\mathrm{n}=9)$ & $1.59 \pm 0.33 \quad(n=13)$ \\
\hline$(\mathrm{HgT})_{\mathrm{P}}\left(\mathrm{nmol.g}^{-1}\right)$ & High (winter) & nd & $2.34 \pm 0.67 \quad(n=14)$ & $1.21 \pm 0.45 \quad(n=9)$ & $0.44 \pm 0.21 \quad(n=11)$ \\
\hline
\end{tabular}




\begin{tabular}{|c|c|c|c|c|c|}
\hline & Low (summer) & $\begin{array}{c}1.08 \pm 0.72 \\
(n=5)\end{array}$ & $1.85 \pm 0.37(\mathrm{n}=8)$ & $0.88 \pm 0.62 \quad(n=8)$ & $0.24 \pm 0.13(n=13)$ \\
\hline \multirow[t]{2}{*}{$\mathrm{Fe}_{\mathrm{ox}}\left(\mu \mathrm{mol} \cdot \mathrm{g}^{-1}\right)$} & High (winter) & nd & $97 \pm 30(13)$ & nd & nd \\
\hline & Low (summer) & $111 \pm 37(5)$ & $112 \pm 73(8)$ & $125 \pm 65(4)$ & $17 \pm 11(3)$ \\
\hline \multirow[t]{2}{*}{$\mathrm{Mn}_{\mathrm{ox}}\left(\mu \mathrm{mol} . \mathrm{g}^{-1}\right)$} & High (winter) & nd & $3.63 \pm 0.83(13)$ & nd & nd \\
\hline & Low (summer) & $6.70 \pm 2.26(5)$ & $4.70 \pm 1.94(8)$ & $6.24 \pm 1.08$ & $3.95 \pm 0.99$ (3) \\
\hline \multirow[t]{2}{*}{$\left(\mathrm{Hg}_{\mathrm{ox}}\right)_{\mathrm{P}}\left(\mathrm{pmol} \cdot \mathrm{g}^{-1}\right)$} & High (winter) & nd & $98 \pm 35(n=13)$ & nd & nd \\
\hline & Low (summer) & $188 \pm 65 \quad(n=5)$ & $141 \pm 59(n=8)$ & $162 \pm 29(n=4)$ & $241 \pm 41 \quad(n=3)$ \\
\hline
\end{tabular}


Table 3. Averages and standard deviations of mercury concentration (dry weight) in the plankton collected in summer in the Seine bay (plume and marine area).

\begin{tabular}{ccc}
\hline Plankton diameter & Total Hg (nmol.g $\left.{ }^{-1}\right)$ & $\begin{array}{r}\text { Monomethylmercury }\left(\mathrm{pmol} . \mathrm{g}^{-1}\right) \text { and } \\
\text { percentage of the total Hg }\end{array}$ \\
\hline $1 \mathrm{~mm}$ & $0.25 \pm 0.08(\mathrm{n}=3)$ & $46 \pm 27(\mathrm{n}=3) ; 18.4 \%$ \\
$1 \mathrm{~mm}-150 \mu \mathrm{m}$ & $0.37 \pm 0.11(\mathrm{n}=3)$ & $23 \pm 17(\mathrm{n}=2) ; 6.2 \%$ \\
$150 \mu \mathrm{m}-40 \mu \mathrm{m}$ & $0.59 \pm 0.13(\mathrm{n}=3)$ & - \\
$40 \mu \mathrm{m}-20 \mu \mathrm{m}$ & $0.69 \pm 0.10(\mathrm{n}=3)$ & $26(\mathrm{n}=1) ; 3.8 \%$ \\
\hline
\end{tabular}




\section{APPENDIX}

Appendix A: Dissolved ligands used in the model with the equilibrium constants according to Guentzel et al. (1996).

\begin{tabular}{|c|c|c|}
\hline Dissolved ligands & Equilibrium & $\begin{array}{c}\text { Constant } \\
\left(\log _{10}\right)\end{array}$ \\
\hline \multirow{4}{*}{$\begin{array}{l}\text { Chlorides: } \\
\text { (calculated from data set) }\end{array}$} & $\mathrm{Hg}^{2+}+\mathrm{Cl}^{-} \Leftrightarrow \mathrm{HgCl}^{+}$ & 7.2 \\
\hline & $\mathrm{Hg}^{2+}+2 \mathrm{Cl}^{-} \Leftrightarrow \mathrm{HgCl}_{2}$ & 14 \\
\hline & $\mathrm{Hg}^{2+}+3 \mathrm{Cl}^{-} \Leftrightarrow \mathrm{HgCl}_{3}^{-}$ & 14.9 \\
\hline & $\mathrm{Hg}^{2+}+4 \mathrm{Cl}^{-} \Leftrightarrow \mathrm{HgCl}_{4}^{2-}$ & 15.6 \\
\hline \multirow{4}{*}{$\begin{array}{l}\text { Hydroxides: } \\
\text { (calculated from pH) }\end{array}$} & $\mathrm{Hg}^{2+}+\mathrm{OH}^{-} \Leftrightarrow \mathrm{Hg}(\mathrm{OH})^{+}$ & 10.6 \\
\hline & $\mathrm{Hg}^{2+}+2 \mathrm{OH}^{-} \Leftrightarrow \mathrm{Hg}(\mathrm{OH})_{2}$ & 21.8 \\
\hline & $\mathrm{Hg}^{2+}+3 \mathrm{OH}^{-} \Leftrightarrow \mathrm{Hg}(\mathrm{OH})_{3}^{-}$ & 20.9 \\
\hline & $\mathrm{Hg}^{2+}+4 \mathrm{OH}^{-} \Leftrightarrow \mathrm{Hg}(\mathrm{OH})_{4}^{2-}$ & 25.4 \\
\hline \multirow[t]{2}{*}{$\begin{array}{l}\text { Sulfates: } \\
\text { (measurements)) }\end{array}$} & $\mathrm{Hg}^{2+}+\mathrm{SO}_{4}^{2-} \Leftrightarrow \mathrm{HgSO}_{4}$ & 2,5 \\
\hline & $\mathrm{Hg}^{2+}+2 \mathrm{SO}_{4}{ }^{2-} \Leftrightarrow \mathrm{Hg}\left(\mathrm{SO}_{4}\right)_{2}{ }^{2-}$ & 3.6 \\
\hline \multirow{3}{*}{$\begin{array}{l}\text { Bromides: } \\
\text { (calculated from salinity*) }\end{array}$} & $\mathrm{Hg}^{2+}+\mathrm{Br}^{-} \Leftrightarrow \mathrm{Hg}(\mathrm{Br})^{+}$ & 9.6 \\
\hline & $\mathrm{Hg}^{2+}+2 \mathrm{Br}^{-} \Leftrightarrow \mathrm{Hg}(\mathrm{Br})_{2}$ & 18 \\
\hline & $\mathrm{Hg}^{2+}+3 \mathrm{Br}^{-} \Leftrightarrow \mathrm{Hg}(\mathrm{Br})_{3}^{-}$ & 20.3 \\
\hline $\begin{array}{l}\text { Thiols: } \\
\text { (estimated from salinity**) }\end{array}$ & $\mathrm{Hg}^{2+}+\mathrm{RS}^{-} \Leftrightarrow \mathrm{Hg}(\mathrm{RS})^{+}$ & $15-22$ \\
\hline
\end{tabular}

$\left(^{*}\right)\left(\mathrm{Br}^{-}\right)=($salinity/1.807)/(0.00348/79.9) according to Millero (1991).

${ }^{(* *}$ ) Assuming a conservative behavior, the thiol concentrations range from $6.10^{-9} \mathrm{M}$ (for freshwater) to $0.1 .10^{-}$

${ }^{9} \mathrm{Ml}$ (for seawater) according to Tang et al. (2000a and 2000b). The model calculates the thiols speciation (R$\left.\mathrm{SH} / \mathrm{R}-\mathrm{S}^{-}\right)$as a function of the thiols acidity constant (Ka) and the $\mathrm{pH}$ with $\log _{10}(\mathrm{Ka})$ varying from 8.3 to 8.8 , depending on the nature and the size of the radical R of the organic ligand R-SH according to Dyrssen (1988) and Dyrssen and Wedborg (1991). 
Appendix B: Surface complexation parameters used in the simulations

\begin{tabular}{lccc}
\hline Surface complexation parameters & Average & Minimum & Maximum \\
\hline Specific surface area $\left(\mathrm{m}^{2} \mathrm{~g}^{-1}\right)^{*}$ & 5.8 & 3.6 & 8.5 \\
Sites density $\left(\mathrm{mol} . \mathrm{m}^{-2}\right)^{*}$ & $2.5810^{-5}$ & $1.9110^{-5}$ & $3.0310^{-5}$ \\
$\mathrm{Ka}_{2}$ constant* & $1.7810^{-5}$ & $1.5810^{-4}$ & $2.0910^{-6}$ \\
Intrinsic constant* & $10^{8}$ & $10^{5}$ & $10^{12}$ \\
Exchangeable mercury (\%)** & 0.1 & 0.05 & 0.2 \\
\hline
\end{tabular}

$\left(^{*}\right)$ The global surface properties and the surface complexation constants have been measured or estimated by Gonzalez et al. (2001a). The acido-basic property of the Seine river particles show that $\mathrm{Ka}_{1}$ is negligible, since then, only $\mathrm{Ka}_{2}$ is taken in account in the model calculations (Gonzalez et al., 2001a).

(**) The exchangeable mercury fraction has been estimated in an experimental study. Particles from the river, collected upstream the high turbidity zone, were resuspended in filtrated $(0.45 \mu \mathrm{m})$ seawater (33 PSU). Both blanks (seawater without particles) and samples were filtrated again $(0.45 \mu \mathrm{m})$ after 90 min contact. The mobile fraction was calculated as the difference between mercury "dissolved" concentrations from blank and those from samples. See Brevière (2002). 


\section{FIGURES}

Fig. 1. Study area. The stations occupied are indicated by dots. Filled circles were samples during Mercaux 1 and 2 cruises ; the open circles only during Mercaux-1 cruise.

Fig. 2. Winter hydrosedimentary and geochemical settings (Mercaux-1 cruise).

Fig. 3. Summer hydrosedimentary and geochemical settings (Mercaux-2 cruise).

Fig. 4. Total dissolved mercury $\left(\mathrm{HgT}_{\mathrm{D}}\right)$ concentrations in relation to salinity.

Fig. 5. Reactive $\left(\mathrm{HgR}_{\mathrm{D}}\right)$ and gaseous dissolved mercury (DGM) concentrations in relation to salinity. $(*)$ Detection limit: $0.1 \mathrm{pM}$.

Fig. 6. Total particulate mercury $\left(\mathrm{HgT}_{\mathrm{P}}\right)$ concentrations in relation to suspended particulate matter (SPM).

Fig. 7. Total particulate mercury $\left(\mathrm{HgT}_{\mathrm{P}}\right)$ in relation to percentage of particulate organic carbon (POC).

Fig. 8. Relationship between particulate mercury $\left(\mathrm{Hg}_{\mathrm{Ox}}\right)$ and iron and manganese $\left(\mathrm{Fe}_{\mathrm{OX}}\right.$ or $\left.\mathrm{Mn}_{\mathrm{Ox}}\right)$ concentrations in the oxyhydroxide fraction (soluble in ascorbic/citric acid solution at $\mathrm{pH}$ 8).

Fig. 9. Non reactive dissolved mercury $\left(\operatorname{HgNR}_{D}=\operatorname{HgT}_{D}-\mathrm{HgR}_{\mathrm{D}}\right)$ concentrations in relation to salinity.

Fig. 10. Non reactive dissolved mercury $\left(\operatorname{HgNR}_{D}=\operatorname{HgT}_{D}-\operatorname{HgR}_{D}\right)$ in relation to dissolved organic carbon (DOC).

Fig 11. Distribution coefficient of mercury $\left(K_{D}(H g T)=\operatorname{HgT}_{P} / \operatorname{HgT}_{D}\right)$ in relation with (a) salinity and the $K_{D}$ for organic carbon $\left(\mathrm{K}_{\mathrm{D}}(\mathrm{Corg})=\mathrm{POC} / \mathrm{DOC}\right)$.

Fig. 12. Total particulate mercury $\left(\mathrm{HgT}_{\mathrm{P}}\right)$ in relation to the particulate carbon-nitrogen ratio $(\mathrm{C}: \mathrm{N})$.

Fig. 13. Mercury enrichment in the oxyhydroxide fraction (soluble in ascorbic/citric acid solution at $\mathrm{pH}$ 8) in relation with the suspended particulate matter concentration (SPM) in the high turbidity zone.

Fig. 14. Reactive dissolved mercury $\left(\mathrm{HgR}_{\mathrm{D}}\right)$ fraction of total mercury (\%) in relation to salinity from (a) measurements and (b) model calculations.

Fig. 15. Modeling test: (a) Model fitting: correlation between calculated and measured total dissolved mercury $\left(\mathrm{HgT}_{\mathrm{D}}\right)$ concentrations. (b) Calculated and measured total dissolved mercury concentrations in relation to salinity. 


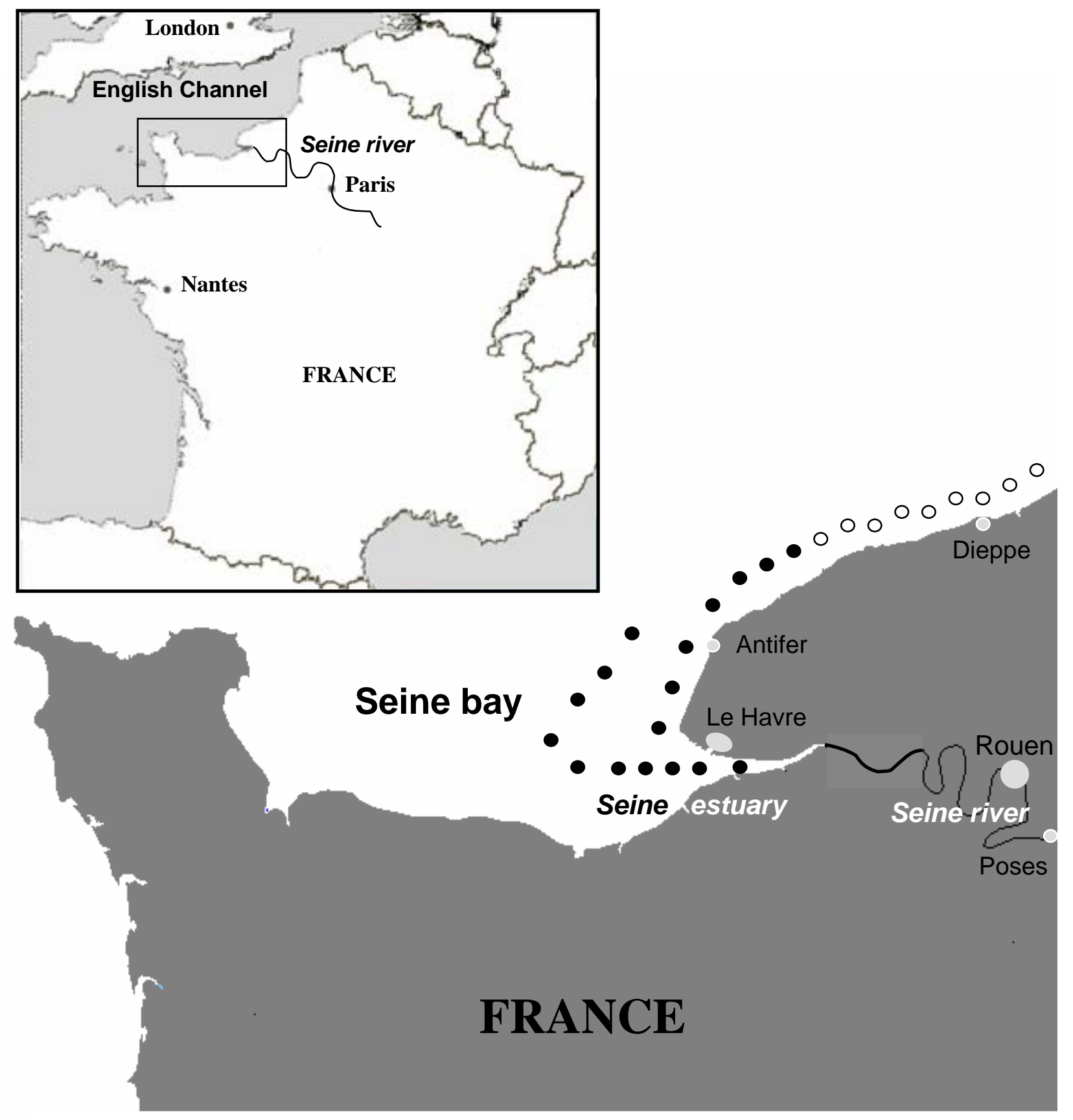

Fig. 1. Study area. The stations occupied are indicated by dots. Filled circles were samples during Mercaux 1 and 2 cruises ; the open circles only during Mercaux-1 cruise 


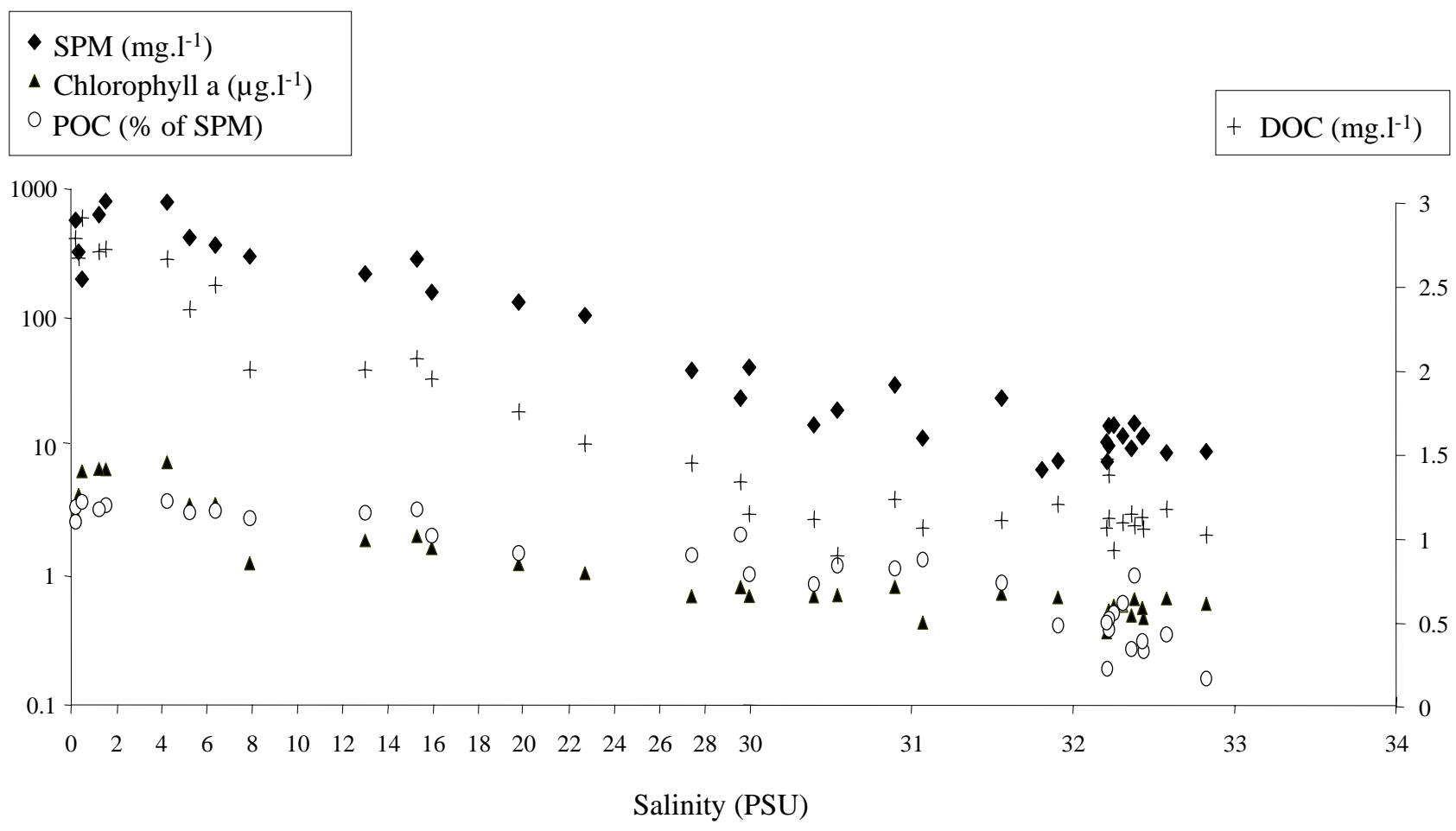

Fig. 2. Winter hydrosedimentary and geochemical settings (Mercaux-1 cruise)

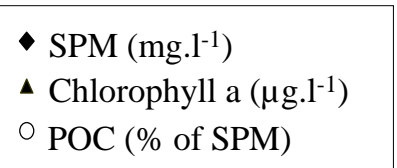$$
+\operatorname{DOC}\left(\mathrm{mg} \cdot \mathrm{l}^{-1}\right)
$$

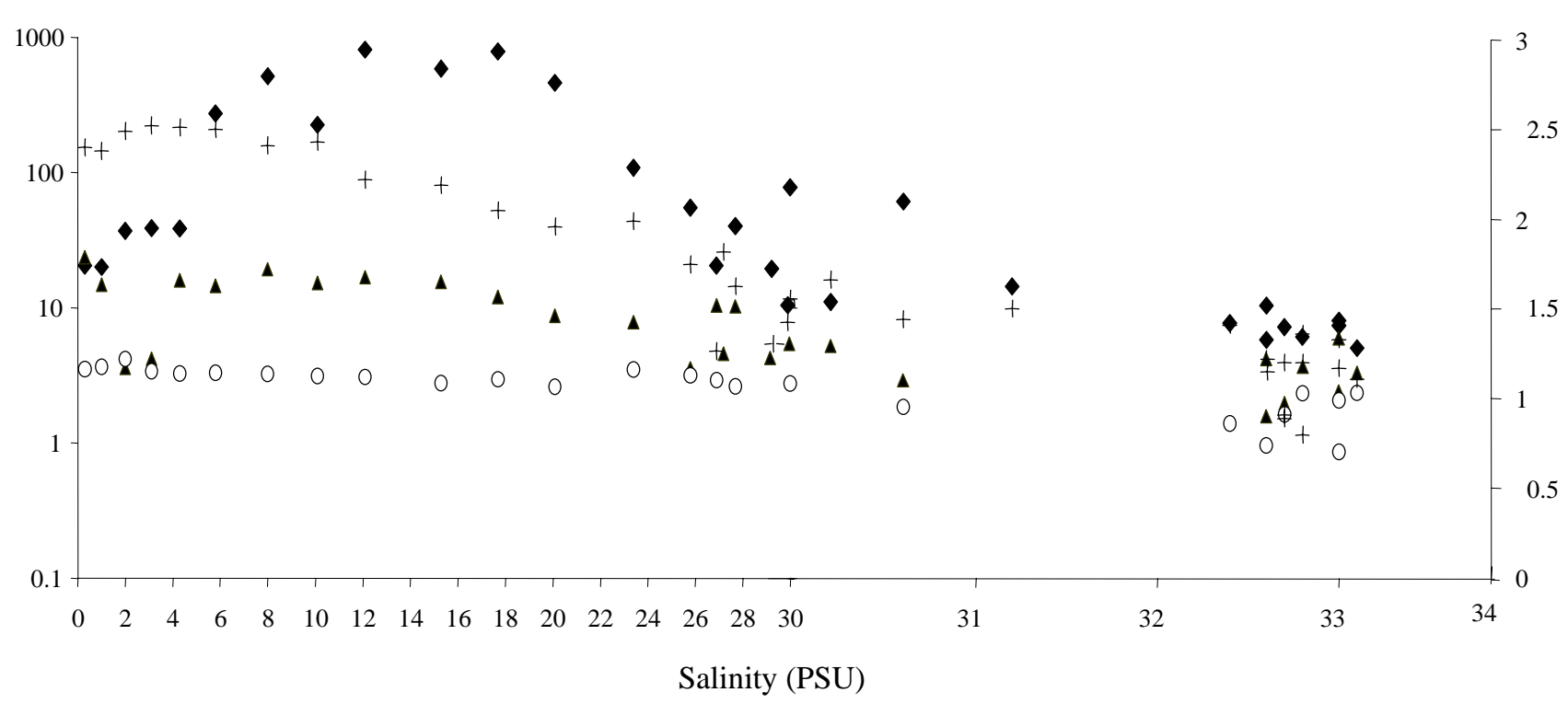

Fig. 3. Summer hydrosedimentary and geochemical settings (Mercaux-2 cruise) 
- HgT $_{\mathrm{D}}$ winter (pM)

$\square \operatorname{HgT}_{\mathrm{D}}$ summer (pM)

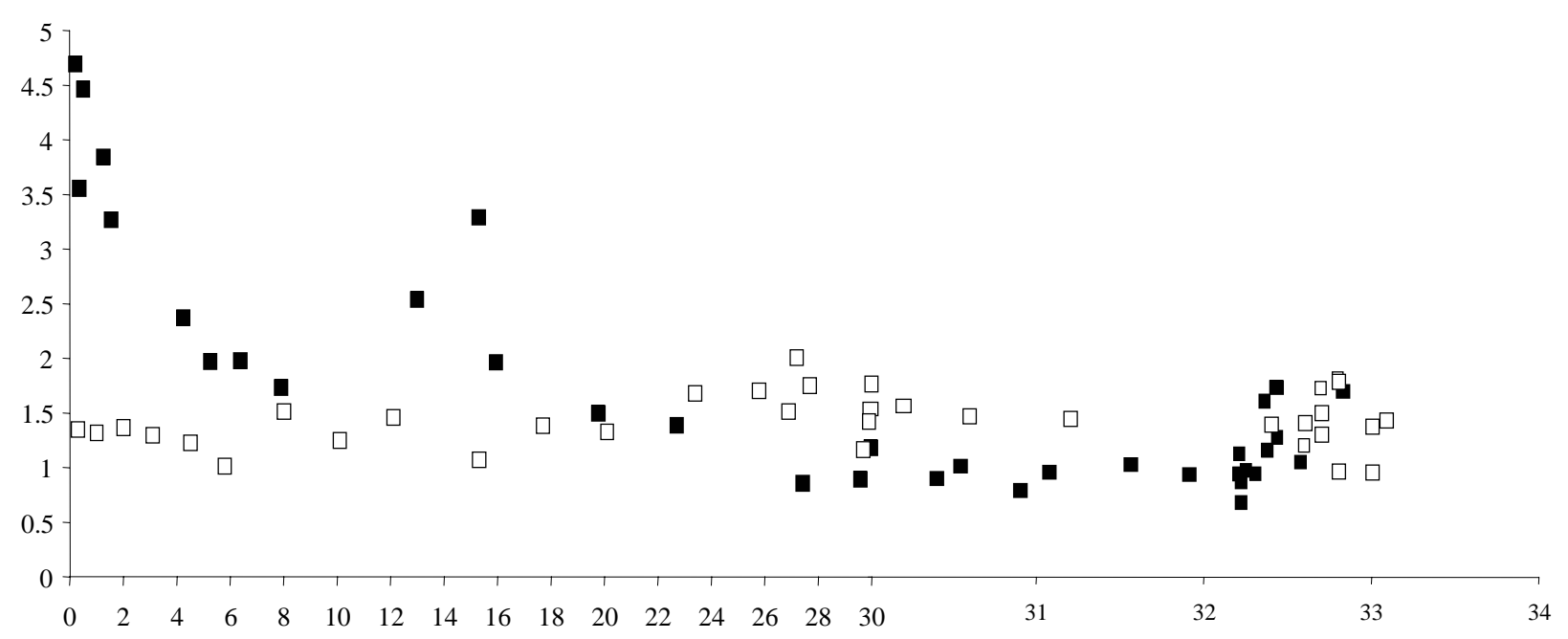

Salinity (PSU)

Fig. 4. Total dissolved mercury (HgTD) concentrations in relation to salinity

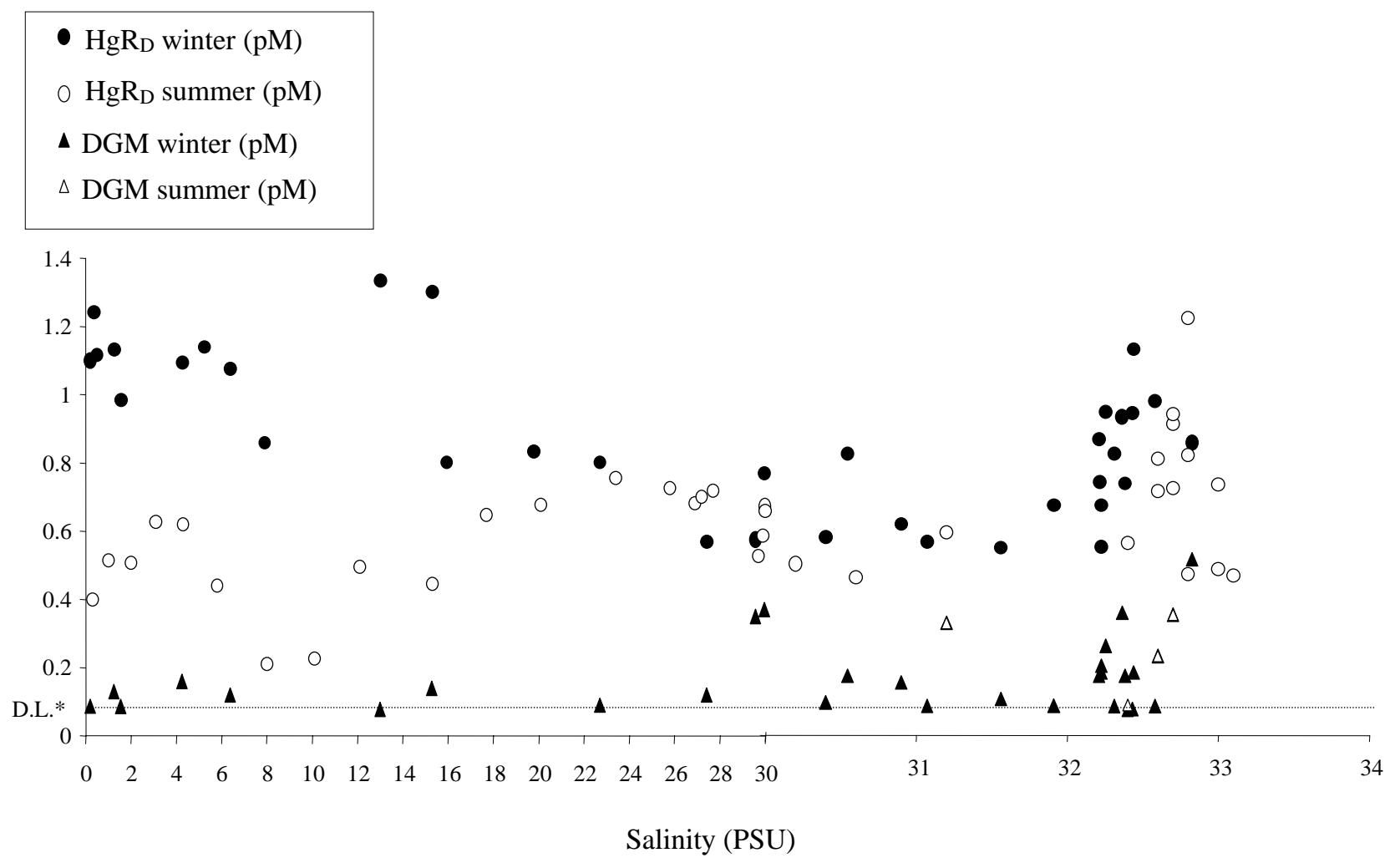

Fig. 5. Reactive (HgRD) and gaseous dissolved mercury (DGM) concentrations in relation to salinity.

$\left.{ }^{*}\right)$ Detection limit: $0.1 \mathrm{pM}$. 


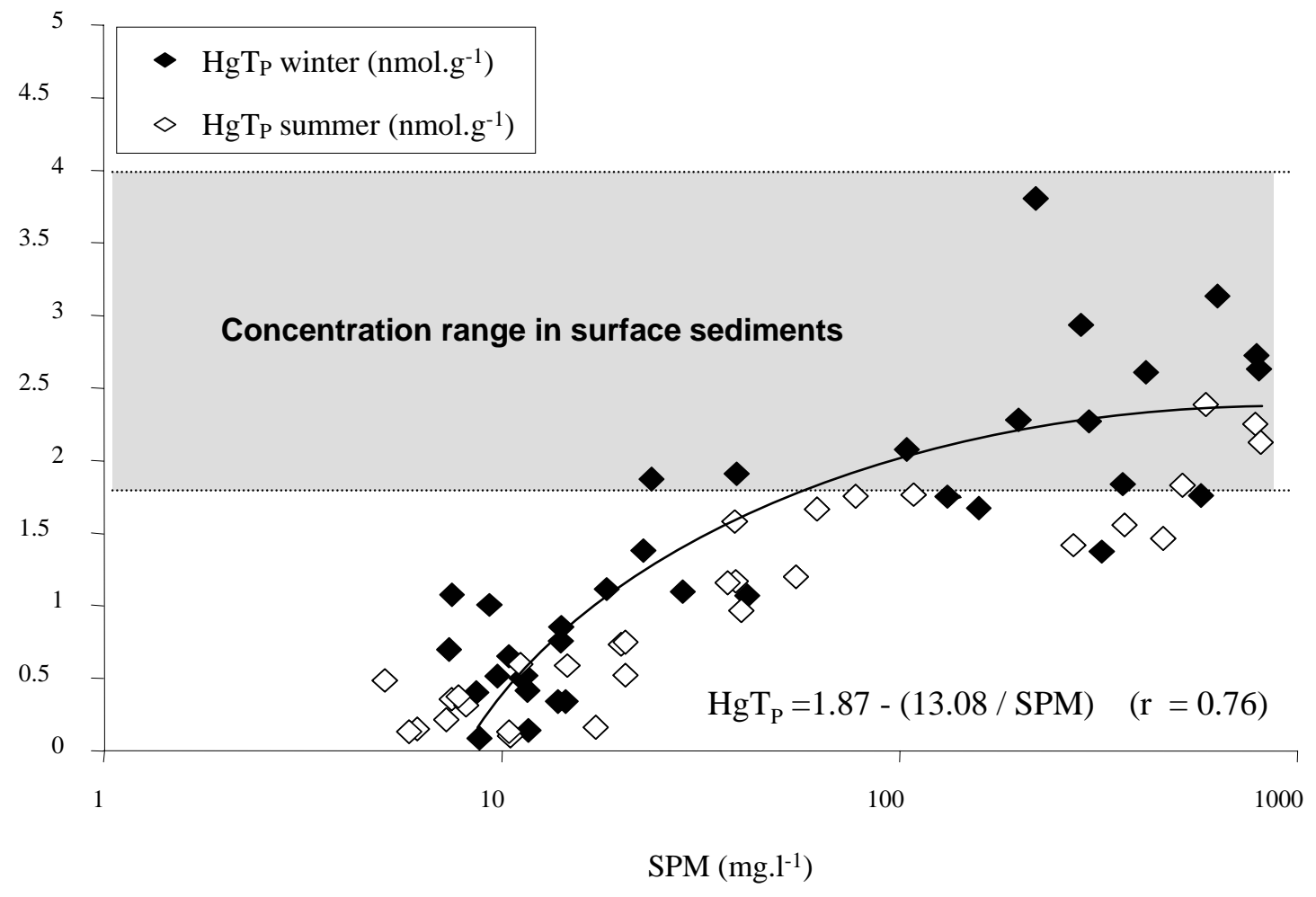

Fig. 6. Total particulate mercury (HgTP) concentrations in relation to suspended particulate matter (SPM) 


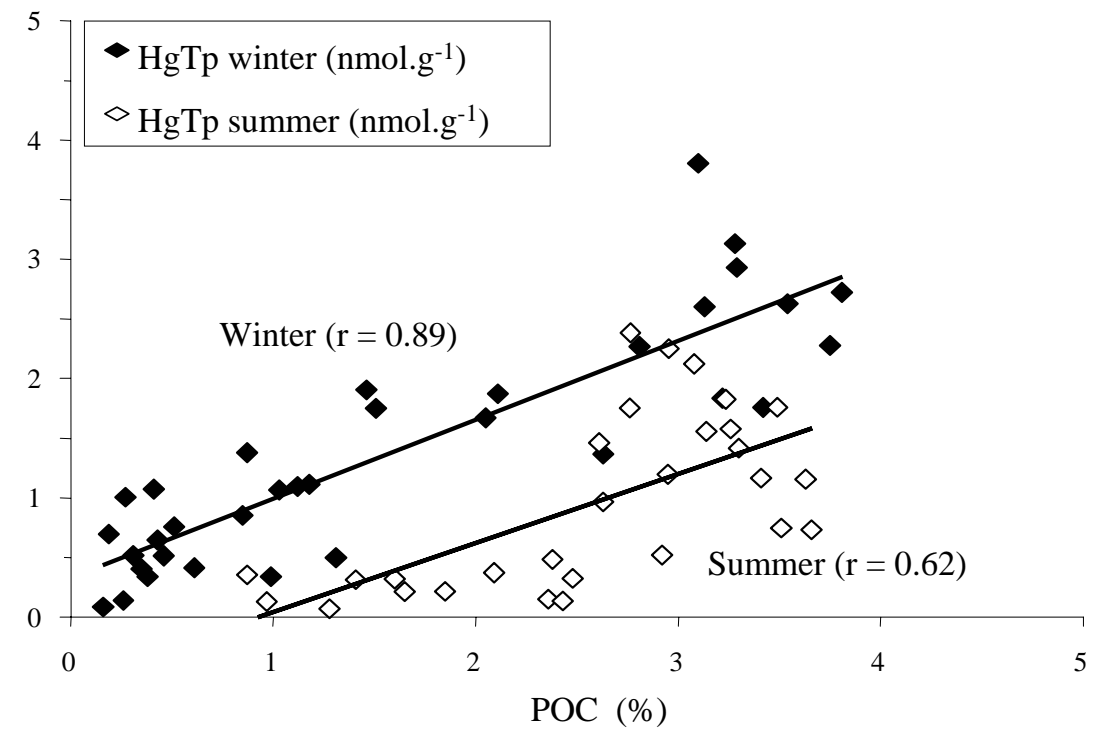

Fig. 7 Total particulate mercury (HgTP) in relation to percentage of particulate organic carbon (POC)

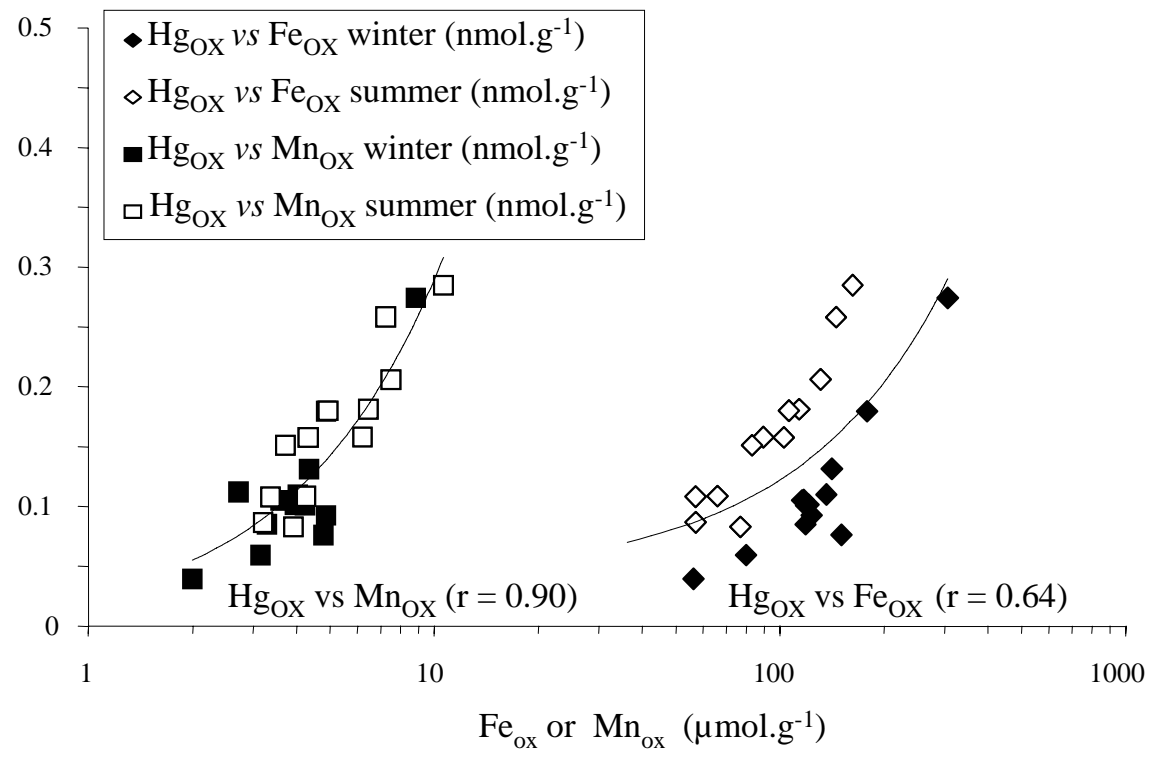

Fig. 8 Relationship between particulate mercury (HgOX) and iron and manganese (FeOX or MnOX) concentrations in the oxyhydroxide fraction (soluble in ascorbic/citric acid solution at $\mathrm{pH} 8$ ) 


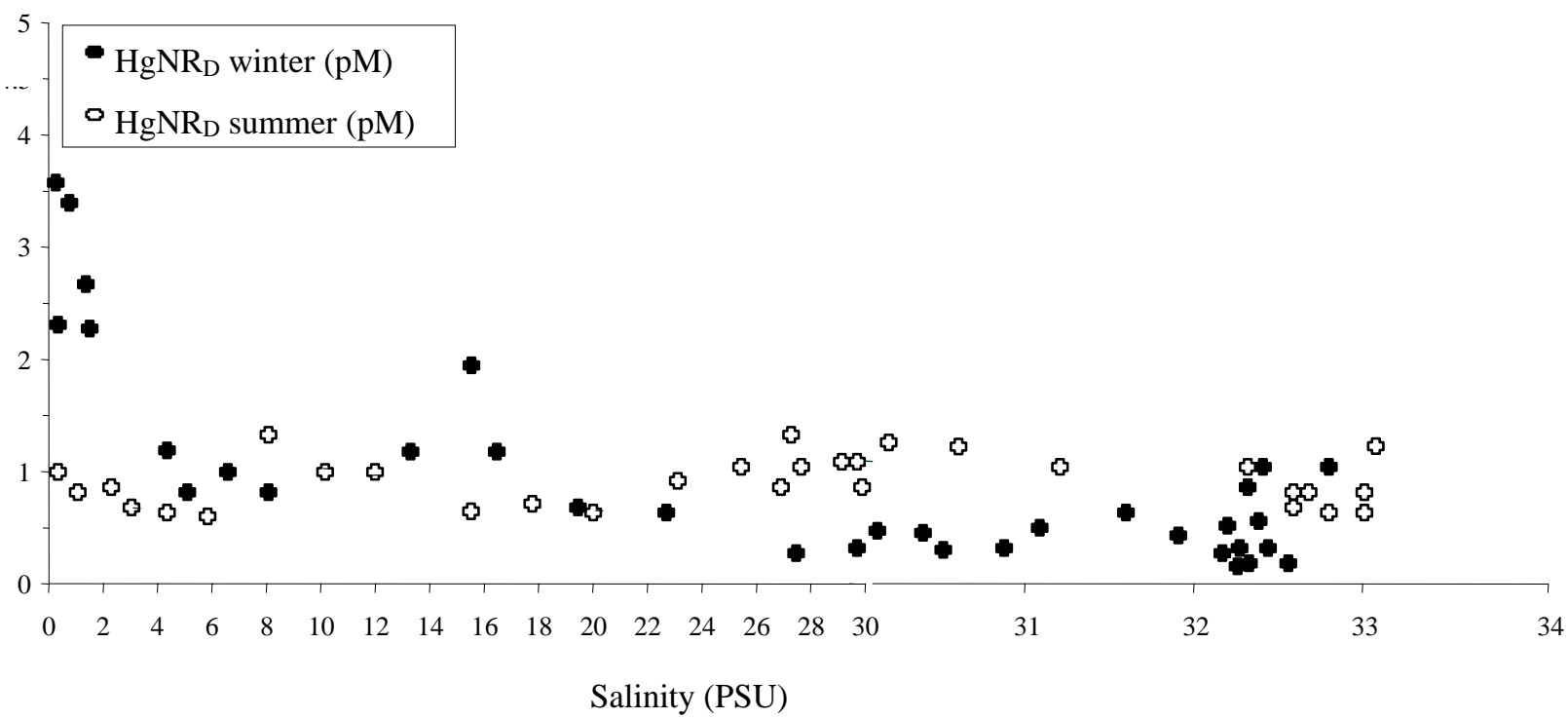

Fig. 9. Non reactive dissolved mercury $(\mathrm{HgNRD}=\mathrm{HgTD}-\mathrm{HgRD})$ concentrations in relation to salinity

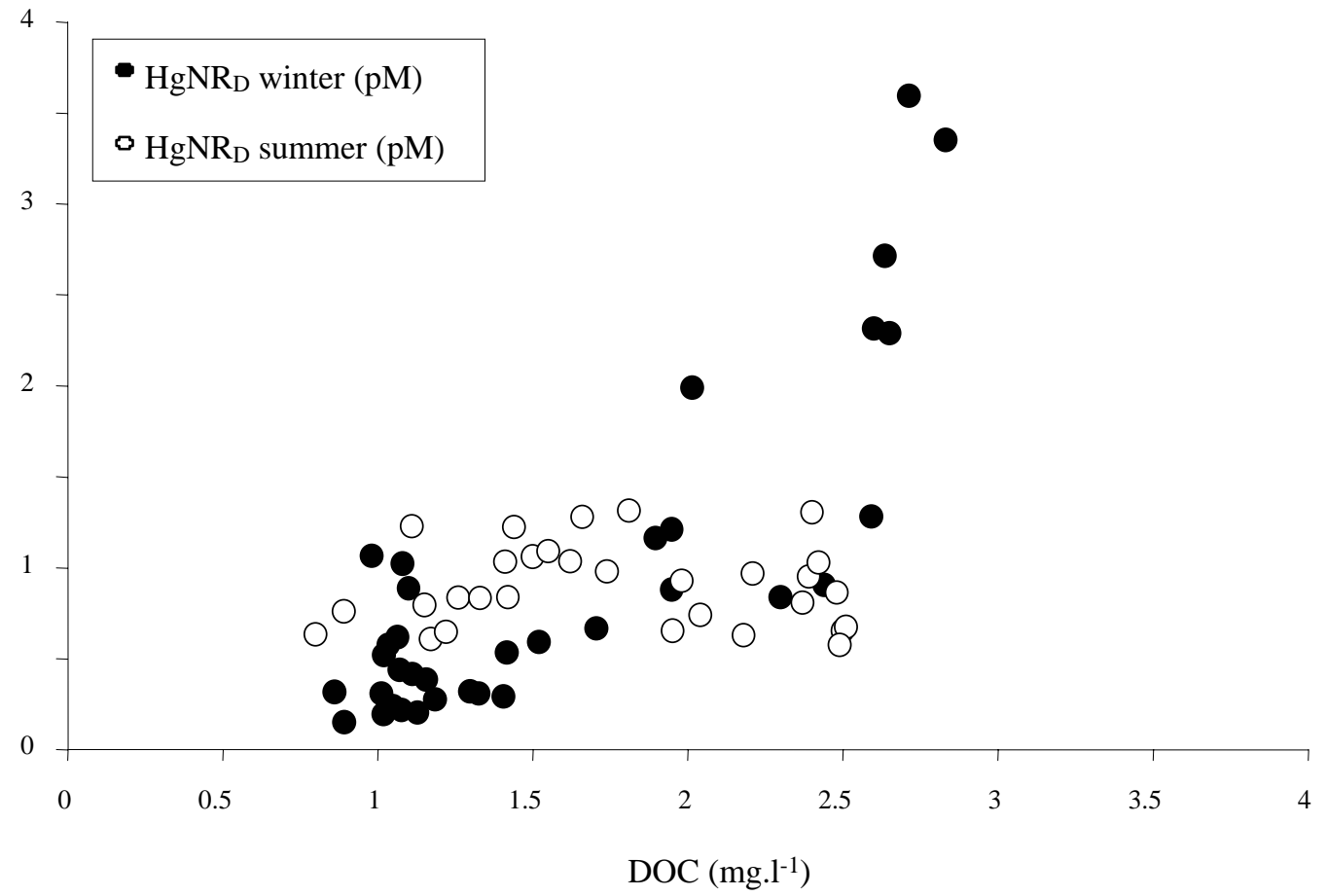

Fig. 10. Non reactive dissolved mercury $(\mathrm{HgNRD}=\mathrm{Hg} T \mathrm{D}-\mathrm{HgRD})$ in relation to dissolved organic carbon (DOC) 

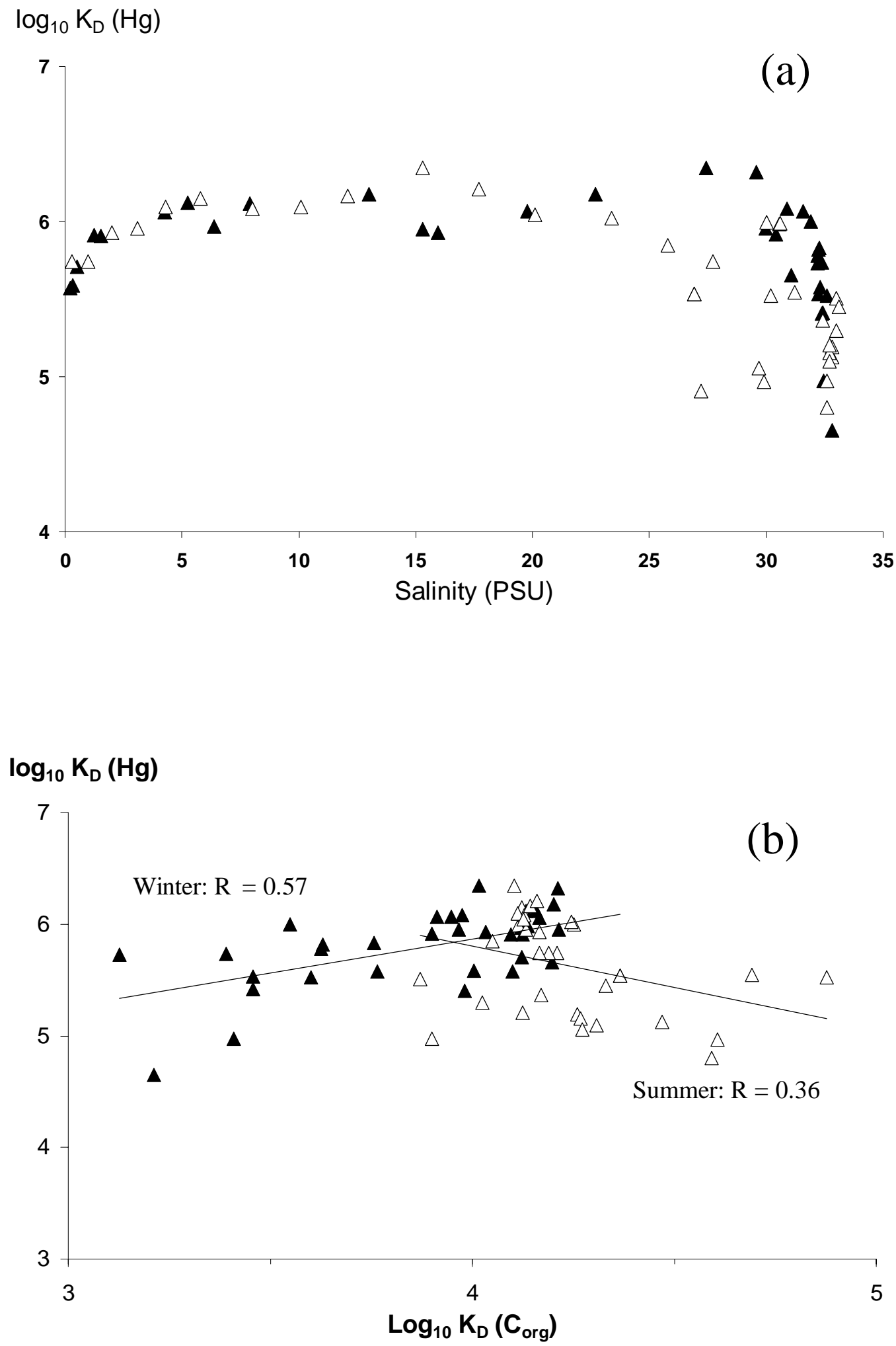

Fig. 11 Distribution coefficient of mercury $(\mathrm{KD}(\mathrm{HgT})=\mathrm{HgTP} / \mathrm{HgTD})$ in relation with (a) salinity and the KD for organic carbon $(\mathrm{KD}$ (Corg) $=$ POC / DOC) 


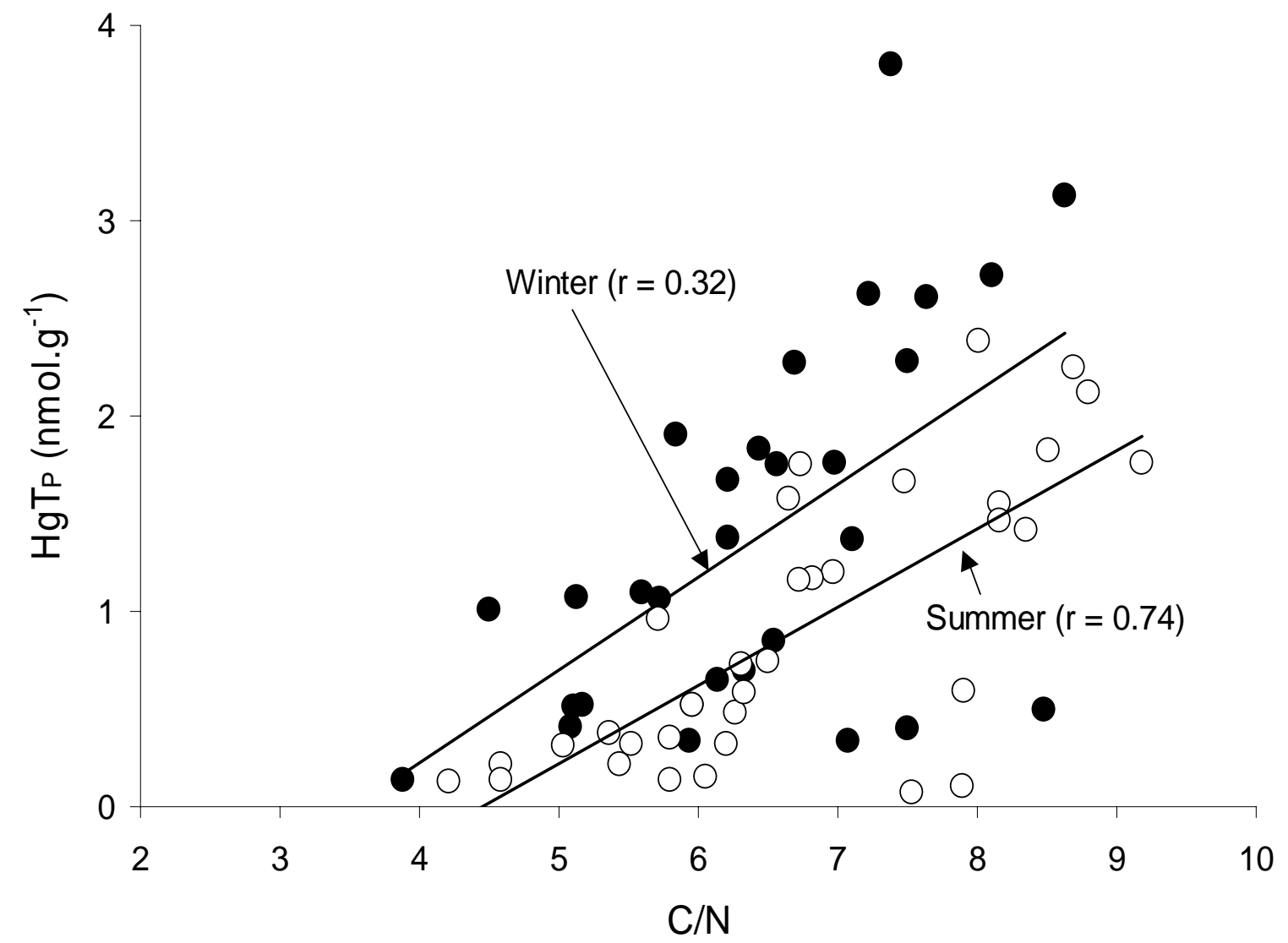

Fig. 12 Total particulate mercury (HgTP) in relation to the particulate carbon-nitrogen ratio (C:N) 


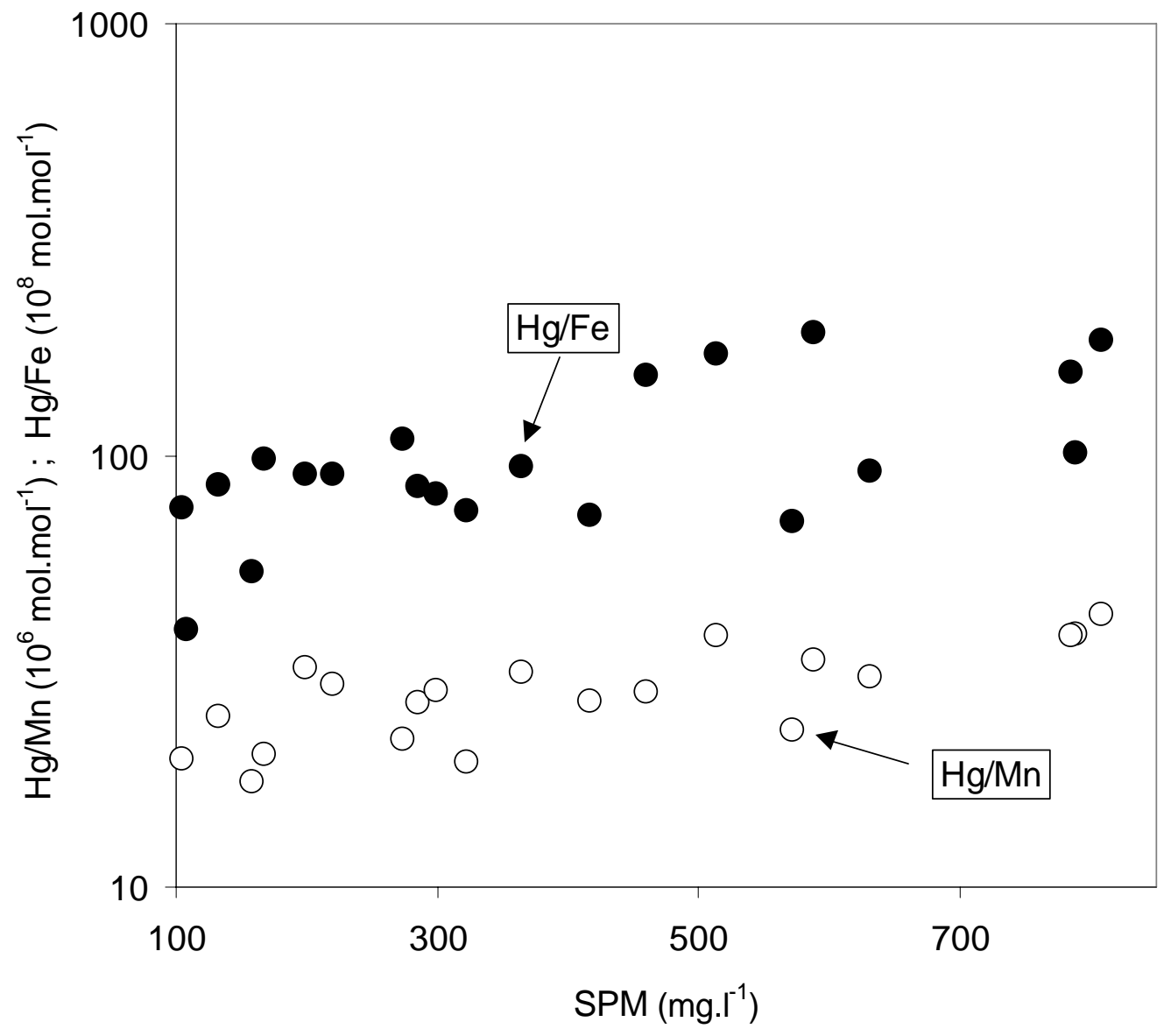

Fig. 13 Mercury enrichment in the oxyhydroxide fraction (soluble in ascorbic/citric acid solution at $\mathrm{pH}$ 8) in relation with the suspended particulate matter concentration (SPM) in the high turbidity zone. 
$\operatorname{HgT}_{\mathrm{D}}$ calculated (pM)
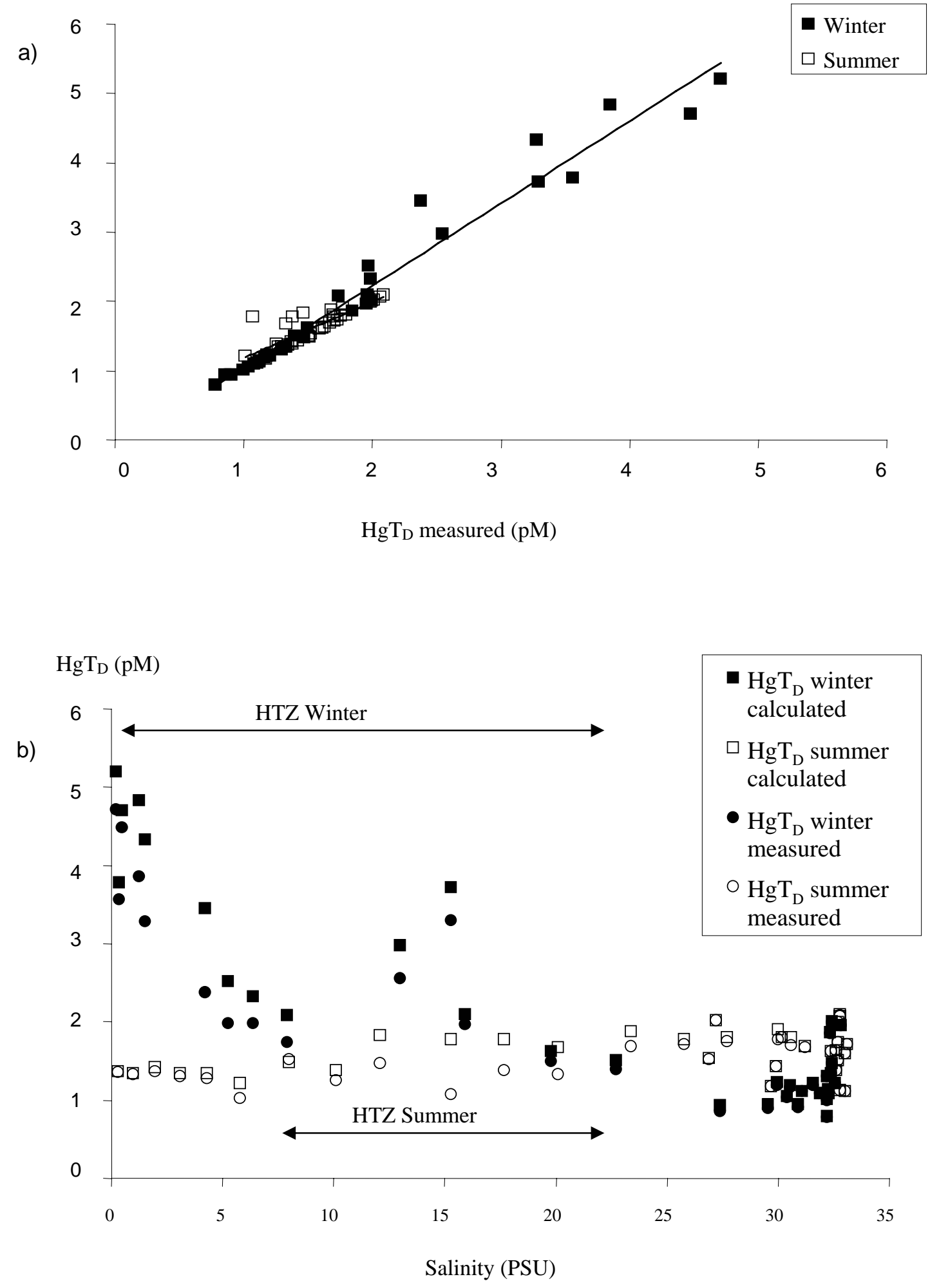

Fig. 14. Reactive dissolved mercury (HgRD) fraction of total mercury (\%) in relation to salinity from (a) measurements and (b) model calculations 
- $\mathrm{HgR}_{\mathrm{D}}$ winter (\%)

o $\mathrm{HgR}_{\mathrm{D}}$ summer (\%)

a) 100

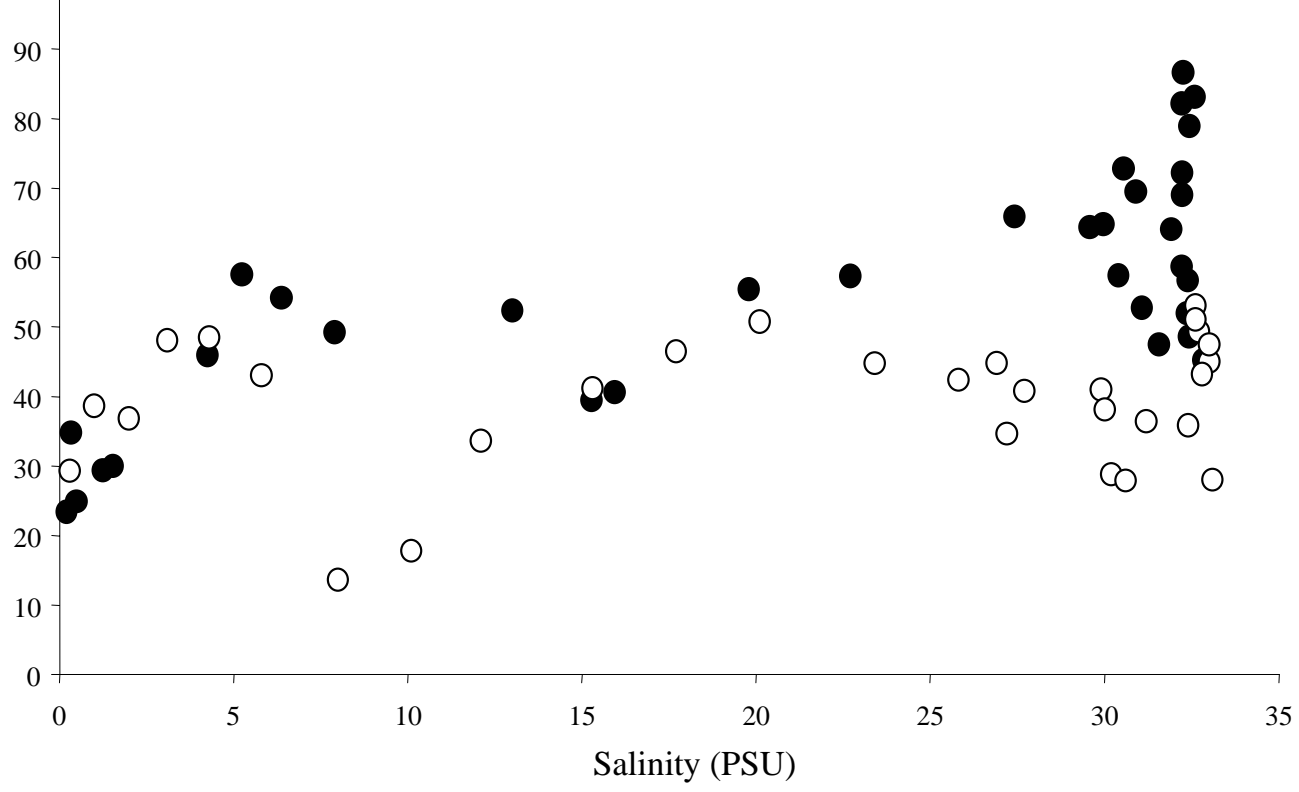

- $\mathrm{HgR}_{\mathrm{D}}$ calculated winter (\%)

○ $\mathrm{HgR}_{\mathrm{D}}$ calculated summer (\%)

b) 100

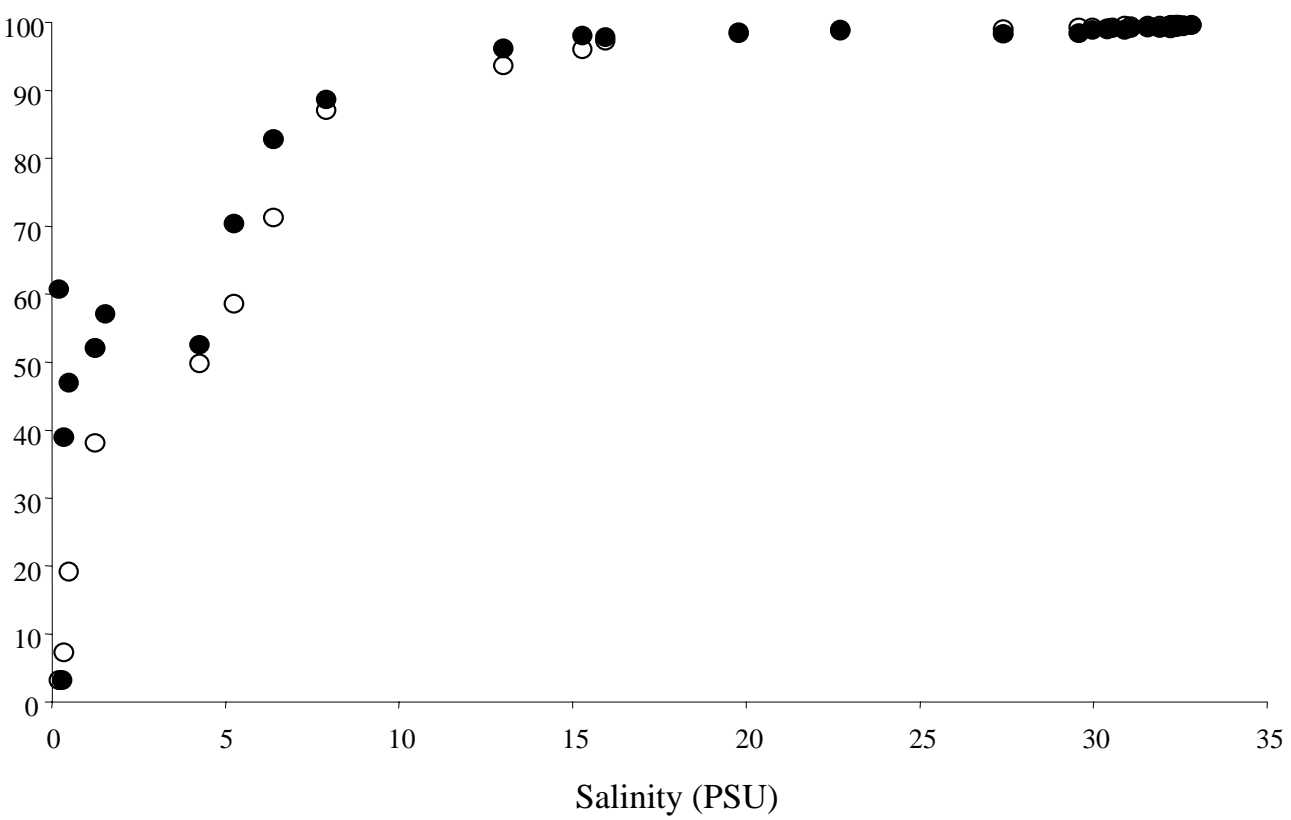

Fig. 15. Modeling test: (a) Model fitting: correlation between calculated and measured total dissolved mercury (HgTD) concentrations. (b) Calculated and measured total dissolved mercury concentrations in relation to salinity 